\title{
Seasonal differences in thermal sensation in the outdoor urban environment of Mediterranean climates - The example of Athens, Greece.
}

\author{
Tseliou, A. ${ }^{1,2}$, Tsiros, I.X. ${ }^{1} \&$ Nikolopoulou, M. ${ }^{3}$ \\ 1. Meteorology Laboratory Agricultural University of Athens, Athens, Greece \\ 2. College of Natural and Health Sciences, Zayed University, Dubai, United Arab Emirates \\ 3. School of Architecture, University of Kent, Kent, UK
}

\begin{abstract}
Outdoor urban areas are very important for cities and microclimate is a critical parameter in the design process, contributing to thermal comfort which is important for urban developments. The research presented in this paper is part of extensive field surveys conducted in Athens aimed at investigating people's thermal sensation in a Mediterranean city. Based on 2313 questionnaires and microclimatic data the current work focuses on the relative frequencies of people's evaluation of the thermal along with the sun and wind sensations between two seasons trying to identify the seasonal differences in thermal sensation. The impact of basic meteorological factors on thermal discomfort with respect to season are also examined, as well as the use of the outdoor environment. Results show that psychological adaptation is an important contributing factor influencing perception of the thermal environment between seasons. In addition, the thermal sensation votes during the cool months show that individuals are satisfied to a great extend with the thermal environment whereas the combination of high air temperature, strong solar radiation and weak wind lead to thermal discomfort during summertime. As far as the appropriate urban design in the Mediterranean climate is concerned, priority should be given to the warm months of the year.
\end{abstract}

Keywords: thermal sensation; adaptation; outdoor thermal comfort; urban climate;

\section{Introduction}

The investigation of the various environmental parameters that influence, determine or alter the thermal sensation in public areas has become an important issue during the last years. Air temperature, mean radiant temperature, humidity, and wind speed along with the personal parameters of metabolic heat generated by human activity and clothing worn by a person are the basic fundamental factors which affect the human response to the thermal environment (Fanger 1970). Thermal environments greatly influence thermal sensation since they determine the heat exchange between the human body and its environment. When an individual experiences thermal stress causing discomfort, it can create heat-related symptoms such as fatigue, headaches, nausea, confusion, cramping, and reduced capacity to work with potential for heat stroke or exhaustion (Vanos et al 2010). Thermal comfort is defined as 'the condition of mind that express satisfaction with the thermal environment' (ASHRAE 1996) and researchers attempt to predict the thermal environment that will lead to thermal comfort based on the above mentioned environmental and behavioural factors. In the past, environments were often assessed only in terms of air temperature but this approach is insufficient since it ignores the other five parameters (Parson 1993). 
Several studies have been carried out to investigate the thermal comfort conditions through field surveys in various urban areas and climatic characteristics worldwide, e.g. in Sydney (Spagnolo and De Dear 2003), Dhaka (Ahmed 2003), Ghardaia (Ali-Toudert and Mayer 2006), Sri Lanka (Emmanuel 2007), Taiwan (Lin 2009), , Equador (Johansson and Yahia 2011), Damascus (Yahia and Johansson 2012), , , Hong Kong (Cheng et al. 2012), Phoenix (Declet-Barreto et al. 2013), Singapore (Yang et al. 2013), Israel (Pearlmutter et al (2014). Considerable research has also been conducted in Europe. Following the early work of Nikolopoulou et al (2001) in the UK, Nikolopoulou and Lykoudis (2006) investigated the thermal comfort conditions in fourteen European cities. Knez and Thorsson (2006) investigated how differences in culture between Sweden and Japan might affect the thermal sensation perception. Oliveira et al. (2007), conducting simultaneous questionnaire surveys and weather monitoring in an open area in Lisbon, showed that thermal comfort can be maintained with temperatures well above the standard values defined for indoor conditions. Lenzholzer (2010) compared the 'real' and the perceived microclimate by interviewing visitors in three Dutch urban squares. Kantor and Unger (2010) used the GIS application ArcView, along with microclimatic monitoring, in order to reveal patterns of area usage according to thermal conditions in Hungary. Krüger et al. (2013), comparing the differences in thermal comfort levels between a rural setting and urban sites in Glasgow, showed that the urban sites exhibited a consistent lower level of thermal discomfort during daytime. A recent research work of Kántor et al. (2016) that was conducted in a wide range of geographical regions revealed that thermal sensitivity and neutral temperature values are significantly different between summer and the two transient seasons.

- A comprehensive presentation of the thermal comfort studies that have been conducted across the world the last decades are presented in the review works of Chen and Ng (2012) and Rupp et al. (2015) An earlier review by Nikolopoulou (2011) identified that the majority of previous research is in broad agreement on the difficulty of approaching thermal comfort and adaptation plays an important role. Adaptation is the process of change by which an organism becomes better suited to its environment and can be divided into physical, physiological and psychological (Nikolopoulou, Baker, and Steemers 1999b; Nikolopoulou and Steemers 2003).

The present research work examines seasonal differences in thermal sensation that may occur due to adaptation process. The study is carried out in Athens, a city for which previous research works have been conducted to address thermal comfort issues (e.g. Tseliou et al. 2016; Tsiros and Hoffman 2014; Shashua-Bar, Tsiros, and Hoffman 2012; Charalampopoulos et al. 2012; Charalampopoulos et al. 2014; Nastos and Matzarakis 2013), however only very few studies were based on both environmental monitoring and questionnaire data (e.g. Nikolopoulou and Lykoudis 2007; Tseliou et al. 2013; Pantavou et al. 2013). None of the above mentioned studies, however, has adequately addressed the seasonal differences in thermal sensation that occur due to adaptation process. This was initially addressed by Nikolopoulou and Lykoudis (2006) whereas Tseliou et al. $(2013,2015)$ presented the thermal comfort range and the thermal sensation zones for the warm and the cool months for the microclimate of Athens, respectively.

The present study considers the differences in thermal sensation that occur between the warm and cool months resulting in different perception of the thermal environment, evaluating the combined effect of basic meteorological parameters for the two seasons of the Mediterranean climate of the city of Athens. The effect of the basic meteorological parameters on thermal discomfort with respect to season is examined along with the use of the outdoor environment. In addition, the logistic regression model is adopted and applied to determine the 
thermal sensation zones for the warm and the cool months taking into consideration the combined influence of four basic environmental parameters.

\section{Study areas}

The study was conducted in three neighborhood public spaces that consist of typical resting-places (Fig. 1). Athens (37058'46" N 23042'58" E), has a Mediterranean, mild humid climate with dry warm and hot summers. Fig 2 presents the mean monthly temperature values, as well as, the monthly relative humidity (\%).(www.hnms.gr, Tsiros and Hoffman 2013). According to the climatic data (Fig 2), the year can be split into two seasonal periods, the cool months lasting from October to April and the warm months from May to September. The ventilation of

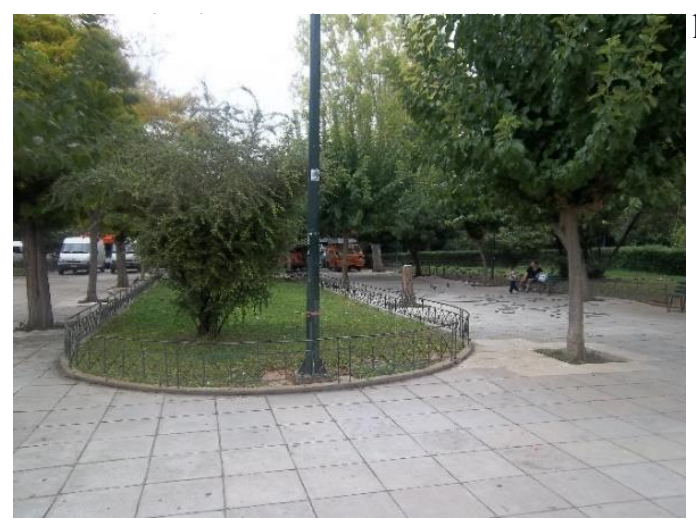

a. Square I

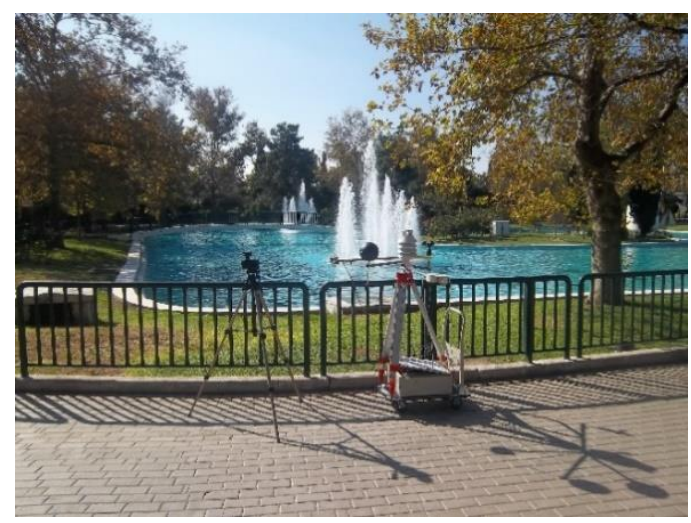

c. Park low wind speed regime. (Tsiros and Hoffman 2013; Santamouris et

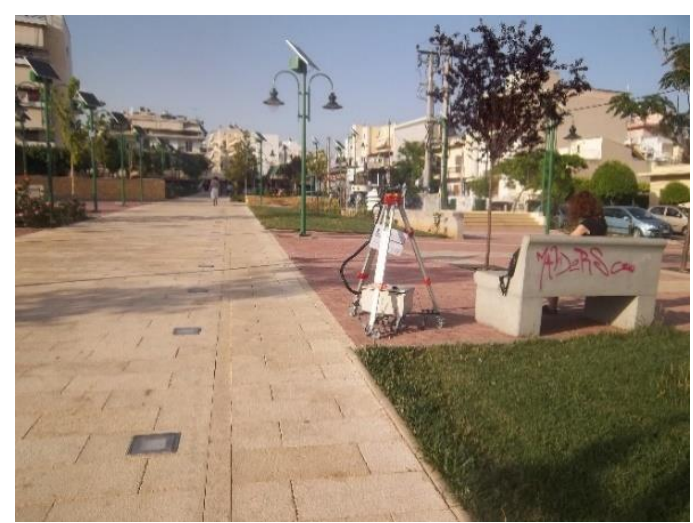

b. Square II

Fig 1 The study areas (a. Square I, b. Square II, c. Park) 


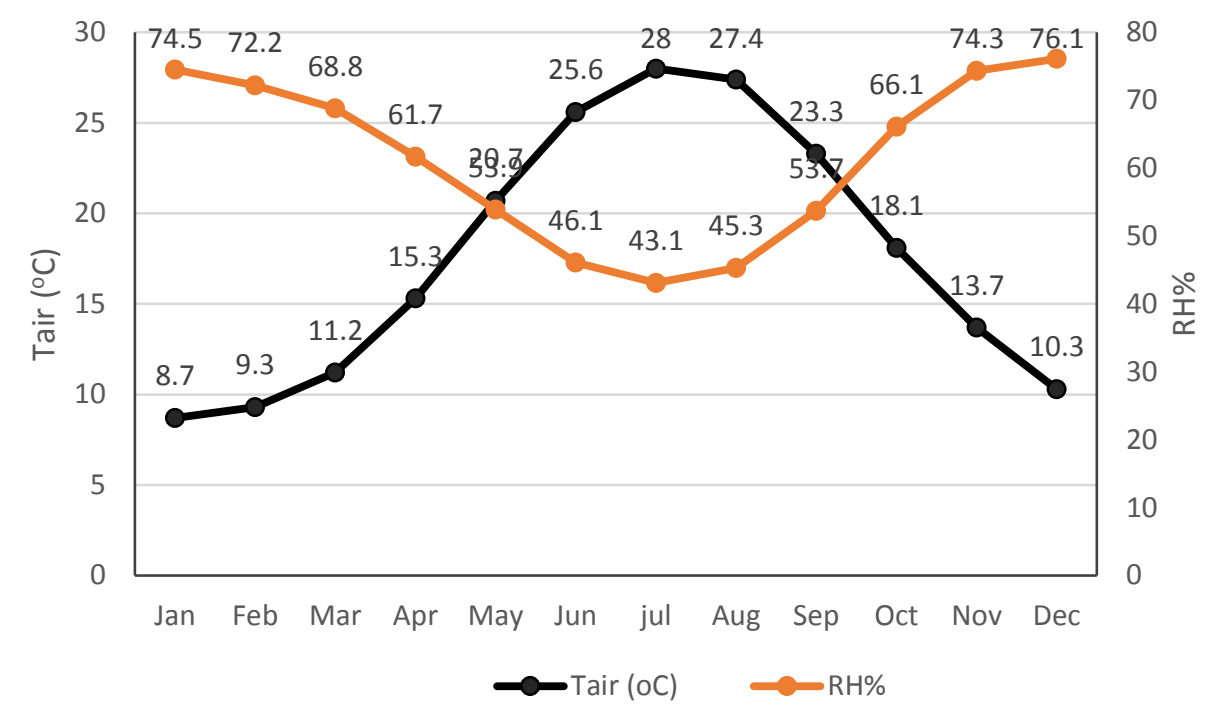

Fig 2 Monthly mean air temperature (Tair ${ }^{\circ} \mathrm{C}$ ) and Relative humidity (RH\%) in Athens (Sourse: Hellenic National Meteorological Service, www.hnm.s.gr)

\section{Methodology}

\section{Field surveys and data}

The field surveys, consisting of field measurements and structured questionnaire-guided interviews, took place intermittently in the period 2010-2012 at different times of the year to evaluate seasonal differences. More specifically, they were conducted during the months of October, November, March and April, representing the cooler months according to the climatic characteristics of Athens and the months May, June, July and September representing the warm months of the year. The duration of the field surveys was affected by the time of year and people visiting the areas. Table 1 presents the specific dates and the duration of the field surveys. As the main aim of the study was to evaluate subjective responses to thermal comfort, such as people's actual thermal sensation, the interviews were adapted to the visiting hours in the various spaces so that people could participate in the surveys. As the examined areas are neighborhood squares relying on local use, there is not a high volume of people crossing through; on the contrary the main user group was locals residing in the surrounding neighborhoods staying at the areas on an average of 1 to 3 hours. This highlights the challenges of gathering questionnaire data during some periods. More specifically, no surveys were conducted during the coldest months of the year, i.e. December to February, due to the limited visits in the areas. Similarly, the open spaces were not used much during the month of August, which traditionally constitutes the summer holiday, with many business closing down for the period and the majority of people taking their annual leave.

During the warm months the measurements were divided into 'morning' (from 10:00LST to 15:00LST) and 'evening' (from 17:30LST - 20:00LST), as visits of the local population are very limited between the hours of 15:30LST and 17:00LST. As this period coincides with the hottest part of the day, cultural norms are followed and pedestrian activity is limited. More specifically, the neighborhood market is closed during these hours and citizens stay indoors, where it is cooler, waiting for the evening hours for the market to open again when the outdoor microclimatic conditions are more favourable and outdoor use becomes more pronounced.

During the cool months field surveys took place from 10:00LST to 17:00LST, as during these hours most people are found outdoors and most activities taking place. After 17:00LST the microclimatic conditions are typically 
cool for this period, it is becoming darker and people prefer to stay indoors. In total, more than the $2 / 3$ of the visitors were interviewed, whereas during the days with extreme weather conditions only few people were visiting the examined areas and all of them were interviewed.

A portable mini weather station was placed at a height of $1.1 \mathrm{~m}$ close to the interviewees recording the microclimatic conditions during the interview (Fig.1b and Fig.1c). For more details on the meteorological instrument and the monitoring procedures the reader should refer to Tseliou et al., 2015.

In order to investigate the actual thermal sensation the questionnaire was divided into three categories including questions/variables on general information ( $\left(1^{\text {st }}\right.$ category), thermal sensation record ( $2^{\text {nd }}$ category) and human perception regarding the examined areas ( $3^{\text {rd }}$ category). Sample of the questionnaire used is presented in Tseliou et al (2015), with the current work focusing only on the $2^{\text {nd }}$ category of the questionnaire which includes the following questions/variables (along with the code numbers of each variable):

- Thermal sensation: Very cold (-3), Cold (-2), Slightly cool (-1), Neither cool nor warm (0), Slightly warm (1), hot (2), Very hot (3)

- Sun sensation: Gloomy(-2),Little sun (-1), Pleasant (0), Sunny (1), Too much sun (2)

- Wind sensation: Stale (-2), Little wind (-1), Pleasant (0), Windy (1), Too much wind (2)

- Thermal comfort: Thermal comfort (0), Thermal discomfort (1)

- Thermal preference: Prefer Warmer (1), No change (0), Prefer Cooler (-1)

Table 1. Dates and times of the field surveys 
Thermal neutrality, identified through the 'neither cool nor warm' vote on the scale of thermal sensation (Actual thermal sensation vote, ATSV), is considered to be the thermal comfort zone. Additionally, thermal comfort is found at conditions where preference is for no change (Fanger 1973). Each possible answer is represented by a code number to facilitate the presentation of the results. The statistical analysis was performed using Statgraphics ${ }^{\circledR}$

\begin{tabular}{|c|c|c|c|c|}
\hline Study areas & Seasonal period & Month & Date of field study & Diurnal \\
\hline \multirow[t]{7}{*}{ Square I } & Cool months & October & $\begin{array}{l}5.10 .10,6.10 .10 \\
20.10 .10,23.10 .10 \\
21.10 .10\end{array}$ & $10: 00-15: 00$ \\
\hline & & November & $\begin{array}{l}4.11 .10,5.11 .10 \\
8.11 .11,11.11 .10 \\
18.11 .10,27.11 .10\end{array}$ & $\begin{array}{l}10: 00-15: 00 \\
10: 00-21: 00\end{array}$ \\
\hline & & March & $\begin{array}{l}6.3 .12,13.3 .12 \\
15.3 .12,20.3 .12 \\
22.3 .12\end{array}$ & $10: 00-15: 00$ \\
\hline & Warm months & May & 9.5 .12 & $17: 30-20: 30$ \\
\hline & & June & $\begin{array}{l}11.6 .11 \\
21.6 .11\end{array}$ & $\begin{array}{l}10: 00-15: 00 \\
17: 30-20: 30\end{array}$ \\
\hline & & July & $\begin{array}{l}1.7 .11 \\
13.7 .11\end{array}$ & $\begin{array}{l}17: 30-20: 30 \\
10: 00-21: 00\end{array}$ \\
\hline & & September & 19.9.11 & $10: 00-15: 00$ \\
\hline \multirow[t]{4}{*}{ Square II } & Cool months & March & $\begin{array}{l}\text { 8.3.12, 9.3.12, } \\
16.3 .12\end{array}$ & $10: 00-15: 00$ \\
\hline & & April & 27.4 .12 & $10: 00-15: 00$ \\
\hline & Warm months & June & $\begin{array}{l}\text { 9.6.11, } \\
17.6 .11\end{array}$ & $\begin{array}{l}10: 00-15: 00 \\
17: 30-20: 30\end{array}$ \\
\hline & & July & $\begin{array}{l}\text { 6.7.11, 11.7.11 } \\
24.7 .11\end{array}$ & $\begin{array}{l}10: 00-15: 00 \\
10: 00-21: 00\end{array}$ \\
\hline \multirow[t]{7}{*}{ Park } & Cool months & October & $\begin{array}{l}8.10 .10,9.10 .10 \\
17.10 .10,24.10 .10 \\
31.10 .10\end{array}$ & $10: 00-15: 00$ \\
\hline & & November & $\begin{array}{ll}1.11 .10 & 13.11 .10 \\
14.11 .10 & 26.11 .10 \\
20.11 .10 & \end{array}$ & $\begin{array}{l}10: 00-15: 00 \\
10: 00-21: 00\end{array}$ \\
\hline & & March & $\begin{array}{ll}10.3 .12 & 17.3 .12 \\
18.3 .12 & 31.3 .12\end{array}$ & $10: 00-15: 00$ \\
\hline & Warm months & May & 19.5.12 & $10: 00-15: 00$ \\
\hline & & June & $23.6 .11 \quad 24.6 .11$ & $10: 00-15: 00$ \\
\hline & & July & $\begin{array}{l}\text { 7.7.11, 15.7.11, } \\
\text { 19.7.11 }\end{array}$ & $\begin{array}{l}10: 00-21: 00 \\
17: 00-20: 30\end{array}$ \\
\hline & & September & $\begin{array}{l}\text { 21.9.11, 24.9.11, } \\
25.9 .11\end{array}$ & $10: 00-15: 00$ \\
\hline
\end{tabular}

and SPSS ${ }^{\circledR}$. To ensure statistical significance among variables the $\chi^{2}$ test, suitable for categorical variables, was used.

The PET (Physiologically Equivalent Temperature) thermal bioclimatic index 
For the purpose of the present study, the PET (Physiologically Equivalent Temperature) index was applied (Hoppe 1984, 1993, 1999; Mayer and Hoppe 1987; Matzarakis 1999; Matzarakis and Mayer 1997; Matzarakis et al. 1999). PET is defined as 'the air temperature of a reference environment in which the heat budget of the human body is balanced with the same core and skin temperature as under the complex outdoor conditions to be assessed' (Hoppe, 1999). The RayMan Pro model was employed as it is a suitable model for the calculation of PET. For more details on the PET index and the Rayman model the reader should refer to Matzarakis 2000; Matzarakis et al. 2007, 2010.

\section{Data overview}

\section{Microclimatic measurements}

The mean air temperature that was recorded from the portable mini weather station presented considerable differences between the two seasons is $31.0^{\circ} \mathrm{C}$ for the warm and $20.0^{\circ} \mathrm{C}$ for the cool months. On the other hand, the difference recorded in wind speed between the two seasons is negligible $\left(0.6 \mathrm{~m} . \mathrm{s}^{-1}\right.$ for the warm months vs. 0.7 $\mathrm{m} \cdot \mathrm{s}^{-1}$ for the cool months).

\section{Questionnaire data}

\section{$1^{\text {st }}$ category - Descriptive statistics}

In total 2313 questionnaires were collected, $37 \%$ corresponding to the warm months and the remaining $63 \%$ to the cool months, representing the higher number of people found outdoors in the cooler period. There was an even distribution between males and females with $48.8 \%$ and $51.2 \%$ respectively. The age-profile of participants was more predominant in the ' $25-35$ ' category, with the different categories represented as follows: child $3 \%$, adolescent 11\%, 18-25 12\%, 25-35 26\%, 35-45 15\%, 45-55 10\%, 55-64 10\% and >65 13\%.

\section{$2^{\text {nd }}$ category - Thermal sensation \& microclimatic conditions}

Examining first the variable 'thermal comfort', where participants evaluate the thermal environment holistically without differentiating for the different meteorological parameters, highlighted that the overwhelming majority is for thermal comfort despite the wide range of environmental conditions for both seasons (almost $87.0 \%$ for the warm and $82.0 \%$ for the cool months) (Fig. 3), which could be indicative of adaptation taking place. 


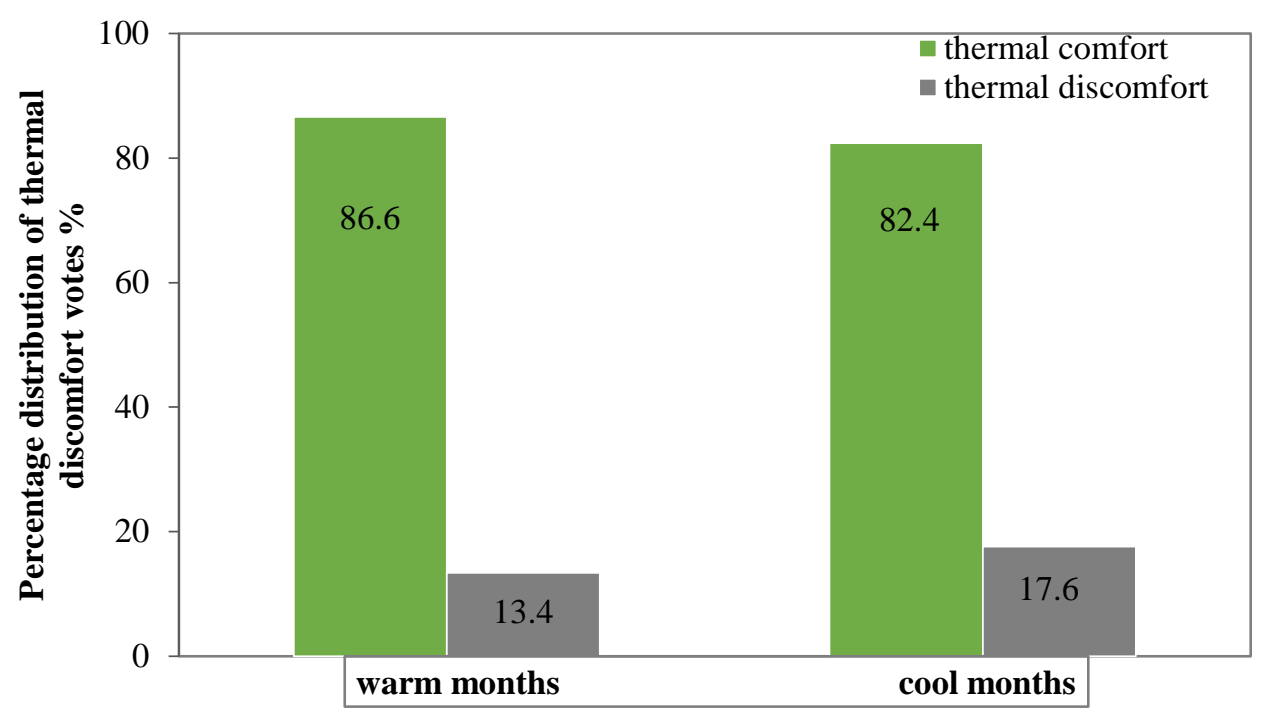

Fig 3 Percentage distribution of the variable 'thermal comfort' for the two seasonal periods

\section{Results and discussion}

\section{Relative frequency of the variable 'thermal comfort' with respect to ATSV, sun and wind sensation zones}

Figures 4, 5 and 6 present the relative frequency of the thermal comfort/thermal discomfort votes of the variable 'thermal comfort' for each ATSV, sun and wind sensation zone, respectively, for both the warm months (a) and the cool months (b).

Figure 4 shows the percentage distribution of thermal comfort/ discomfort votes for each ATSV scale, for the warm months (Fig. 4a) and the cool months (Fig. 4b). Regarding the warm months, Figure 4a shows that the 'hot' and the 'very hot' zones of ATSV concentrate $34.8 \%$ and $50.0 \%$ of the 'thermal discomfort' votes, respectively. The central and the cooler ATSV zones present remarkable high percentages of the overall 'thermal comfort' votes exceeding $96.0 \%$. Regarding the cool months, figure $4 \mathrm{~b}$ reveals that, remarkably, more than the $90.0 \%$ of the 'thermal comfort' votes corresponds to the central zones of ATSV ( -1 to +1$)$. The 'very cold' zone is directly related with the 'thermal discomfort' votes while the 'cold', 'hot' and 'very hot' zones of ATSV concentrate the 57.0\%, $33.0 \%$ and $52.0 \%$ of the 'thermal discomfort' votes, respectively. Figure 5 shows the percentage distribution of thermal comfort/ discomfort votes for each sun sensation zone, for the warm months (5a) and the cool months (5b). For the warm months, Figure 5a reveals that the percentage of 'thermal discomfort' votes increases as we move towards higher sun sensation zones. Thus, the 'little sun' and 'pleasant' sun zones present approximately the same percentage of 'thermal discomfort' votes that is, $5.8 \%$ and $7.5 \%$, respectively whereas the percentage of 'thermal discomfort' votes increases to $25.3 \%$ for the 'sunny' and to $36.2 \%$ for the 'too much sun' zones. As for the cool months (Fig. 5b), the 'pleasant' sun zone is notable related with the 'thermal comfort' votes concentrating the $91.8 \%$ of the votes. Additionally, the percentages of 'thermal comfort' votes are also high and comparatively the same for the other sun zones varying approximately from $65.0 \%$ to $77.0 \%$. Figure 6 shows the percentage distribution of thermal comfort/ discomfort votes for each wind sensation zone, for the warm months (6a) and the cool months $(6 \mathrm{~b})$. For the warm months, Figure 6 a reveals that the percentage of 'thermal discomfort' votes increases as we move towards smaller wind categories. Thus, the 'little wind' and 'windy' zones present approximately the same percentage of 'thermal discomfort' that is, $82.8 \%$ and $85.0 \%$, respectively, whereas it 
increases to $100 \%$ for the 'stale wind' zone. As for the the cool months(Fig 6b), the 'stale' and 'little wind' zones concentrate the $16.9 \%$ and $18.3 \%$ of the 'thermal discomfort' votes, respectively, whereas the 'pleasant' wind zone presents a notable $89.0 \%$ of the 'thermal comfort' votes. The 'windy' and 'too much wind' zones are a little more related with thermal discomfort concentrating the $43.9 \%$ and $37.5 \%$ of the 'thermal discomfort' votes, respectively.

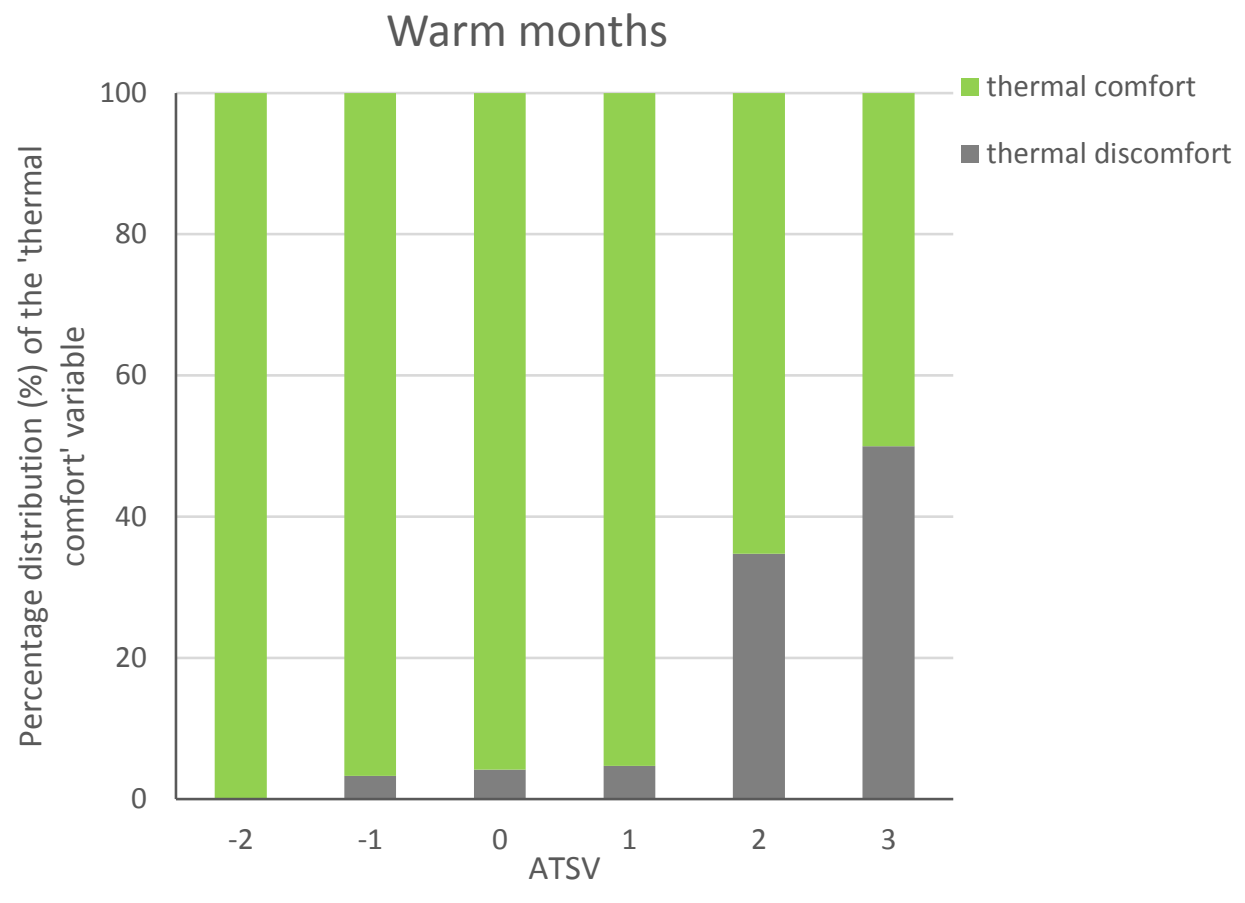

(a)

Cool months

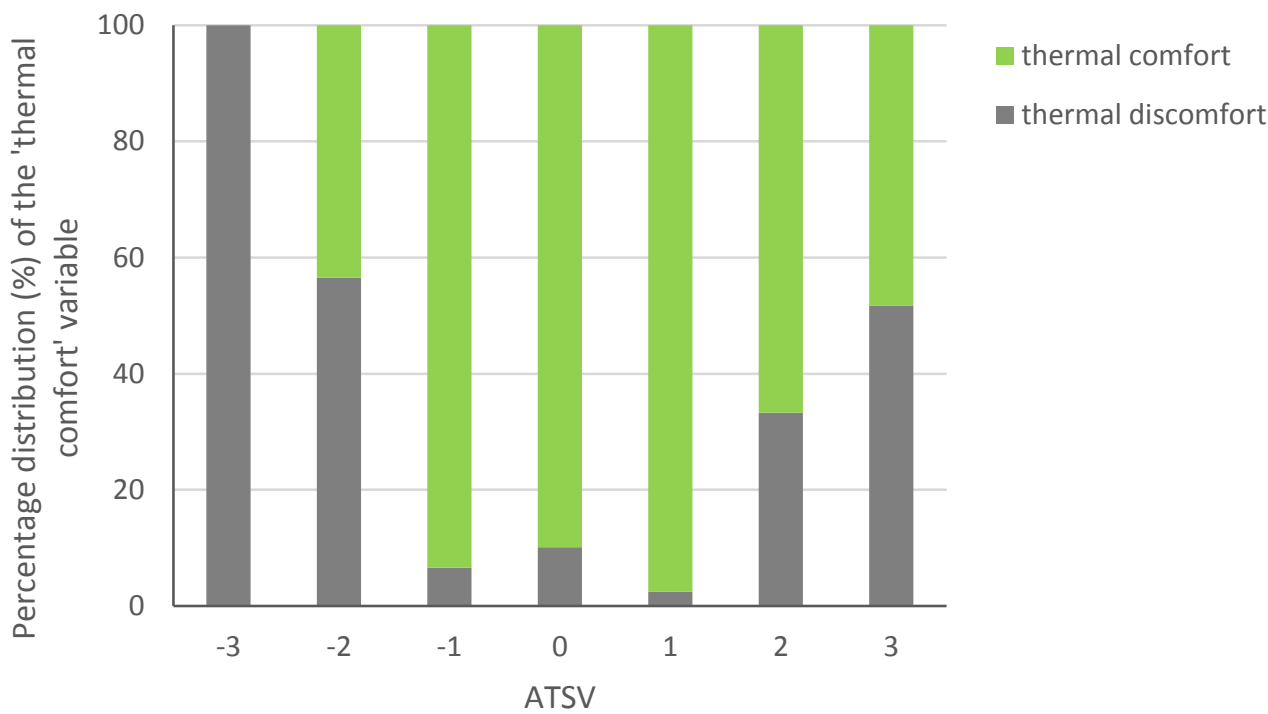

(b)

Fig 4. Percentage distribution of the 'thermal comfort' variable for each ATSV zone for the warm months (a) and the cool months (b) 


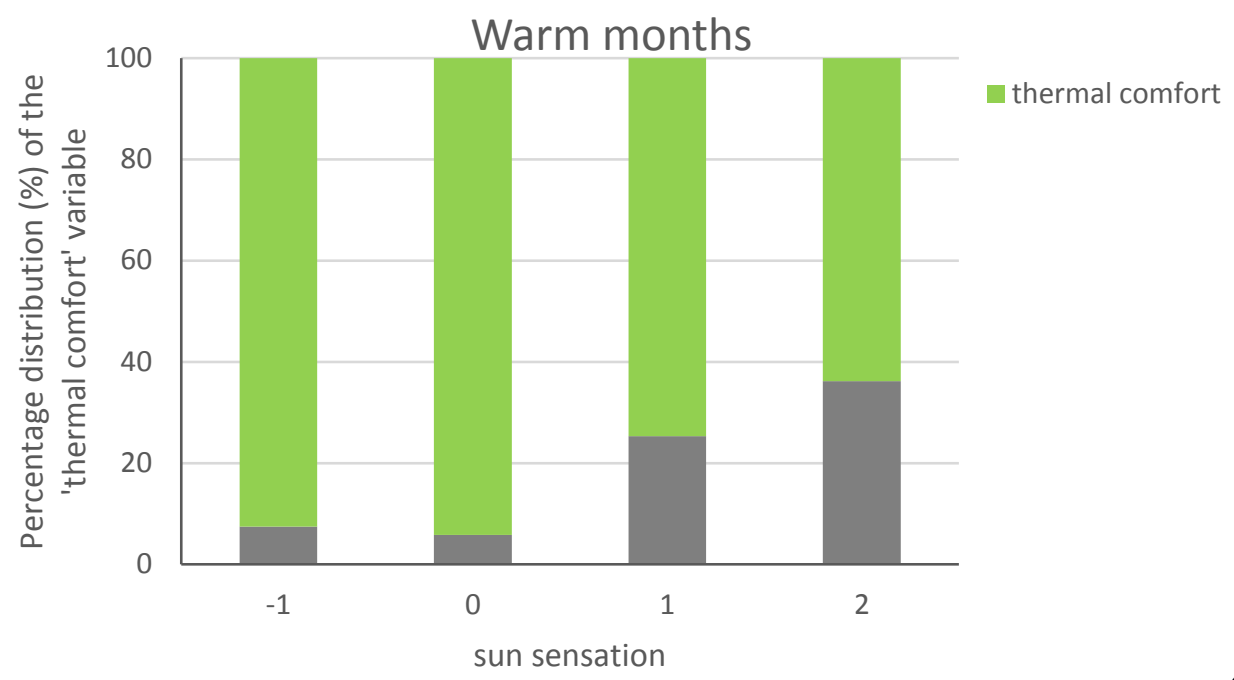

(a)

\section{Cool months}

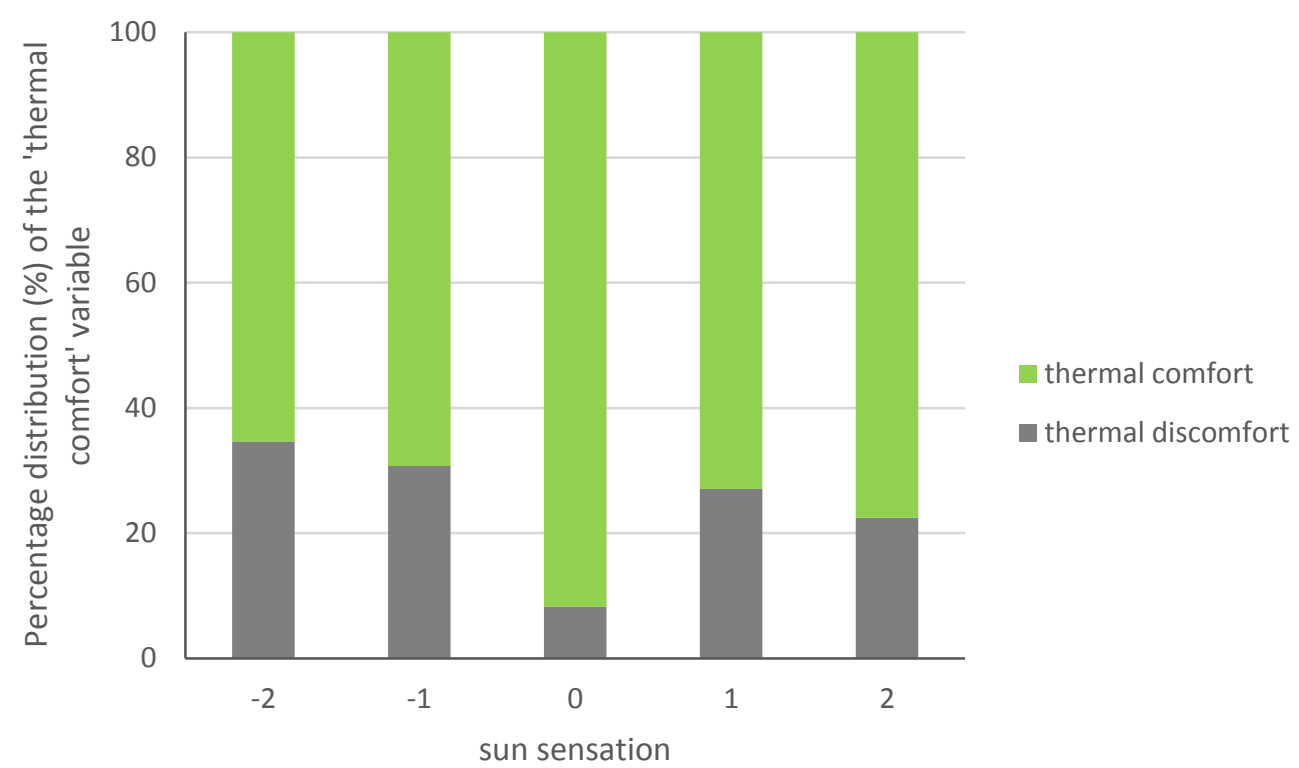

(b)

Fig 5. Percentage distribution of the 'thermal comfort' variable for each sun sensation zone for the warm months (a) and the cool months (b) 


\section{Warm months}

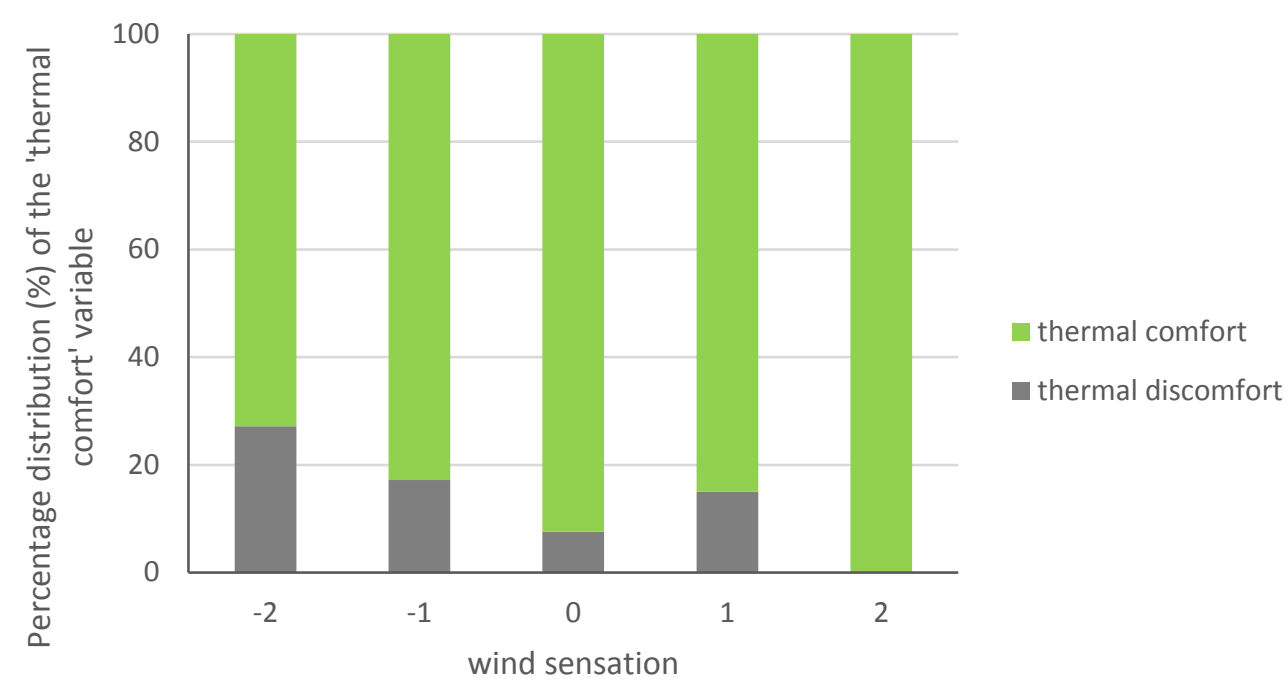

(a)

\section{Cool months}

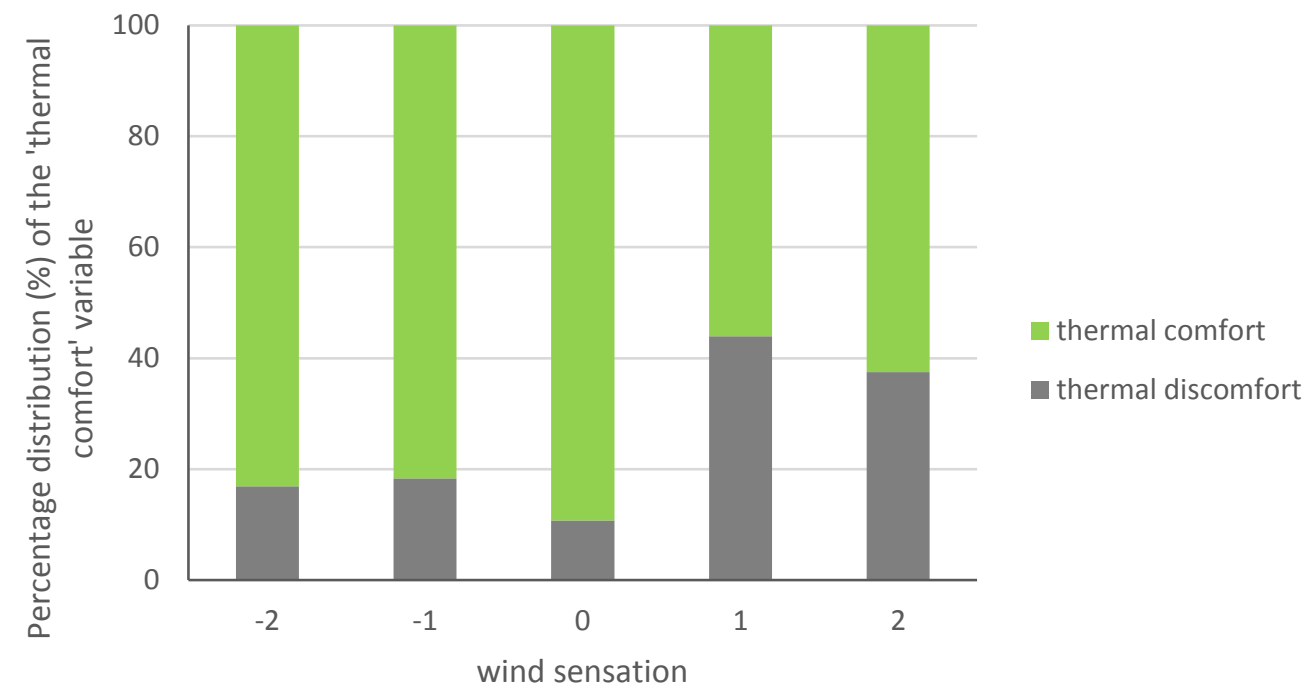

(b)

Fig 6. Percentage distribution of the 'thermal comfort' variable for each wind sensation zone for the warm months (a) and the cool months (b)

\section{Relative frequencies of ATSV, sun and wind between the warm and cool months}

Figures $7 \mathrm{a}, 7 \mathrm{~b}$ and $7 \mathrm{c}$ compare the relative frequency of each category of ATSV, sun sensation and wind sensation for the warm and the cool months, indicating the general tendency of each category for the different variables. Regarding ATSV, the greatest frequency presents the 'neither cool nor warm' which is gathering the $35.0 \%$ out of the total amount of votes (26.7\% during the cool months and $8.34 \%$ during the warm months). Comparing the two seasons, cool months gather three times more 'neither cool nor warm' votes than warm months, implying that the environmental conditions that occur during the specific period satisfy the interviewers more than those occur during the warm months. Next follows a $19.1 \%$ of the total amount of votes that corresponds to the 'slightly warm' 
category (12.0\% during the warm months and $7.0 \%$ during the cool months). Considering that during the cool months the air temperature was on average $10{ }^{\circ} \mathrm{C}$ lower than during the warm months the difference in votes between the two periods is considered to be expected. The extreme ATSV categories ( \pm 3 ) are very small with only $0.39 \%$ ( $0.39 \%$ during the cool months and $0.0 \%$ during the warm months) and $3.93 \%$ ( $2.7 \%$ during the warm months and 1.3 during the cool months), respectively. It is worth mentioning that although the 'hot' category is very similar for both seasons, it is slightly higher for the cool months $(7.0 \%$ of the total votes during the warm months and 9.7\% during the cool months). This can be explained considering that during the cooler months of the year the greater number of people enjoy the outdoor environment during the calmer days of the period, where they find them warmer as the usual resulting in their voting. Considering that the climate of Athens is hot and dry during summer the 'very hot' category would be expected to gather a greater percentage of votes. However, responses such as 'hot is logical for summer' or 'for summer the temperature is good' indicate that participants are well adapted in their thermal environment and the factor of psychological adaptation enables individuals to demonstrate great tolerance in the outdoor environment where all the climatic changes occur naturally.

Likewise, focusing on the cool months the relative frequencies among the 'cold', 'slightly cool', slightly warm' and the 'hot' categories account for almost the same percentage of votes despite the fact that the ambient environment is cooler, especially with respect to the warm months, but warmer with respect to the cool months. Thus, comments such as 'too hot for winter' were quite frequent during the field surveys.

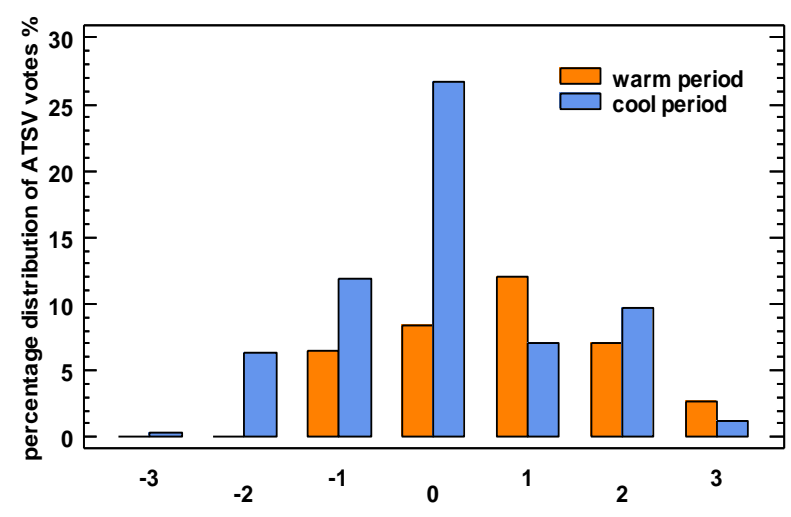

(a)

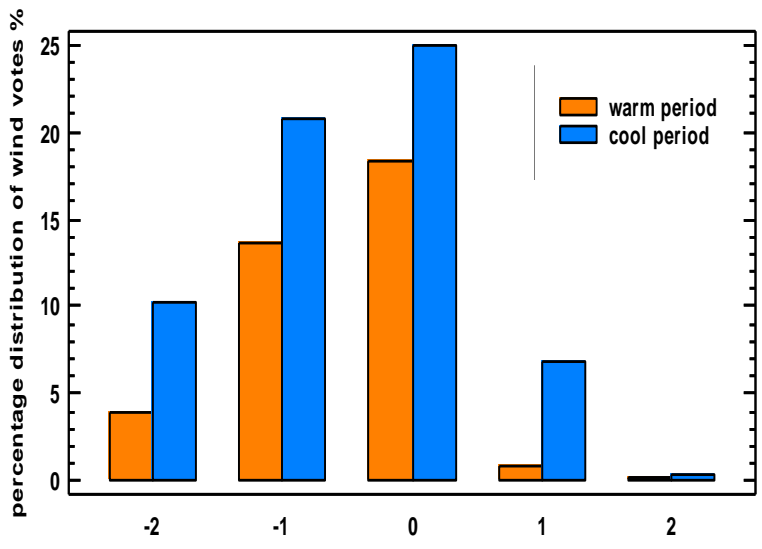

(b)

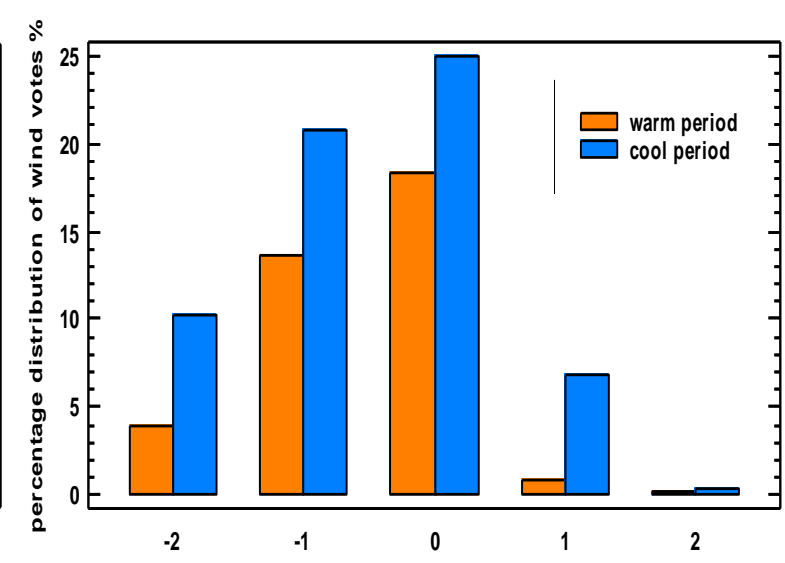

(c)

Fig 7 Comparison of the relative frequency of a. ATSV, b. sun sensation and $\mathbf{c}$. wind sensation votes for the warm and the cool months 
Regarding the variable 'sun sensation', the greatest frequency, $47.2 \%$, accounts for the 'pleasant' category. The $33.7 \%$ of them corresponds to the cool months, implying satisfaction regarding the solar radiation conditions on average of about $400 \mathrm{Wm}^{-2}$. Only $13.5 \%$ is for 'pleasant sun' for the warm months despite the fact that during this period evening field surveys (17:00 - 20:30 LST) were also conducted. This is mostly because during the morning field surveys the average solar radiation was about $800 \mathrm{Wm}^{-2}$. The 'sunny' and the 'too much sun' votes have the same percentage for the two seasons implying cool months in general with plenty of sun. The variable 'wind sensation' follows the same relative frequency among the two seasons. The highest relative frequency is for the 'pleasant' wind, which is $43.2 \%$ ( $25.0 \%$ for the cool months and $18.2 \%$ for the warm months). The 'little wind' category gathers the $34.4 \%$ of the total amount of votes $(13.6 \%$ for the warm months and $20.8 \%$ for the cool months). The extreme 'too much wind' category is negligible for both seasons, which is expected given the very low wind speed throughout the surveys $\left(0.6 \mathrm{~m} . \mathrm{s}^{-1}\right.$ and $0.7 \mathrm{~m} \cdot \mathrm{s}^{-1}$ the warm and the cool months, respectively). It is interesting, that under the same wind speeds that occur during the two seasons, differences in the relative frequencies of wind votes are attributed to the combined effect of air temperature and solar radiation differences, concerning the thermal effects that influence perceptions regarding the wind conditions.

\section{The impact of air temperature, sun and wind to thermal discomfort}

To evaluate the impact of air temperature, solar radiation and wind speed on thermal discomfort the latter was isolated and examined with respect to 'ATSV', 'sun sensation' and 'wind sensation' variables. Figure 8 presents the ATSV percentage distribution for those in thermal discomfort for the different seasons.

Examining the ATSV percentage distribution of the warm months (Fig 8a) it is observed that the extreme votes of ATSV, 'hot' and 'very hot', are directly related with thermal discomfort' votes. $50.0 \%$ of the 'thermal discomfort' votes is gathered in the 'hot' category of ATSV followed by $7.0 \%$ in 'very hot' and $11.4 \%$ in the 'neither cool nor warm' category. The remaining categories of ATSV account for less than $7.0 \%$. As far as the cool months is concerned (Fig 8b), there is not a clear trend in the concentration of the ATSV categories. Thus, an almost equal distribution of votes is observed, that is, $31.0 \%$ in the 'cold' and $28.0 \%$ in the 'hot' category while the 'neither cool nor warm' category is gathering $23.0 \%$ of the votes. Figure $8 \mathrm{c}$ reveals that, for the 'thermal discomfort' votes of the warm months, the warmer ATSV zones are related with remarkable high percentages of 'prefer cooler' votes that exceed the $95 \%$ for the scales ATSV: +2 and +3 . Even the 'neither cool nor warm' scale presents a $75 \%$ of 'prefer cooler' votes. Figure $8 \mathrm{~d}$ reveals that, for the 'thermal discomfort' votes of the cool months the warmer ATSV zones concentrate high percentages of 'prefer cooler' votes that exceed the $65 \%$. Accordingly, the cooler ATSV zones (ATSV: -2 and -3) concentrate notably high percentages of 'prefer warmer' votes that exceed the $84 \%$. Figure 9 presents the 'sun sensation' percentage distribution for those in thermal discomfort for the different seasons. Regarding the warm months, it is clear that the 'sunny' zone is directly related with thermal discomfort. The other sun sensation zones gather almost the same percentage of votes that is $15.0 \%$ to $17.0 \%$. For the cool months the 'little sun' zone concentrates the larger percentage of votes, $46.4 \%$, while the 'pleasant' and the 'sunny' zones gather $25.0 \%$ of the votes. 

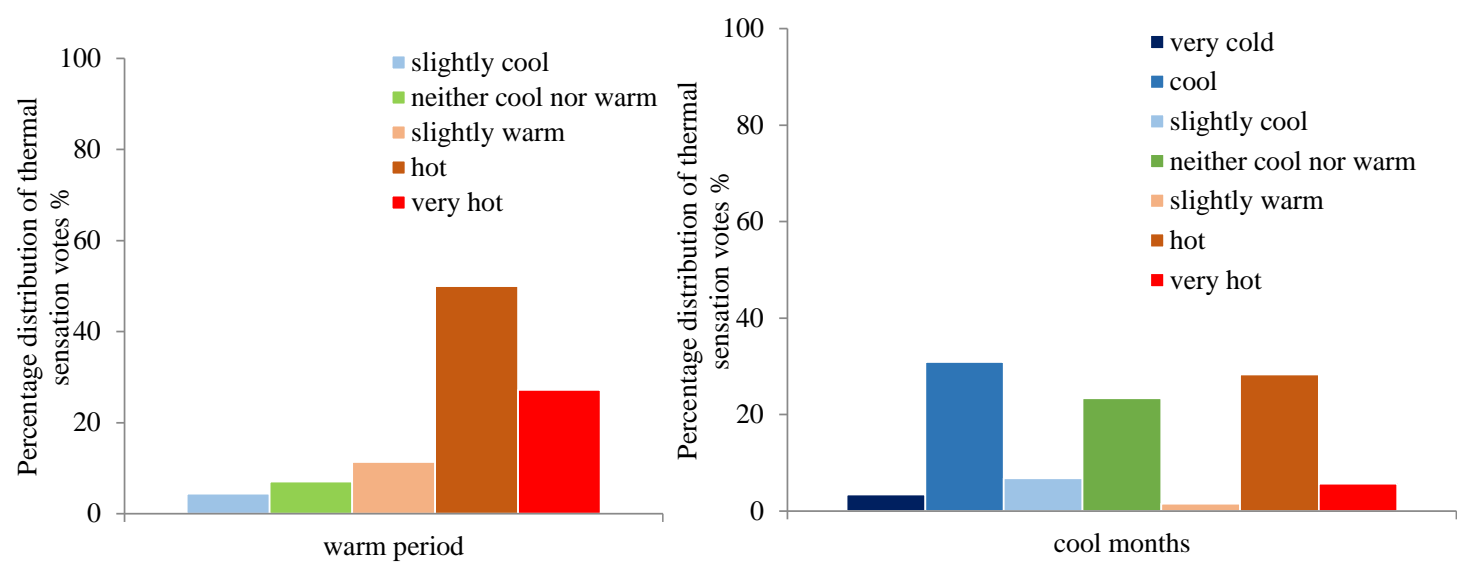

(a)

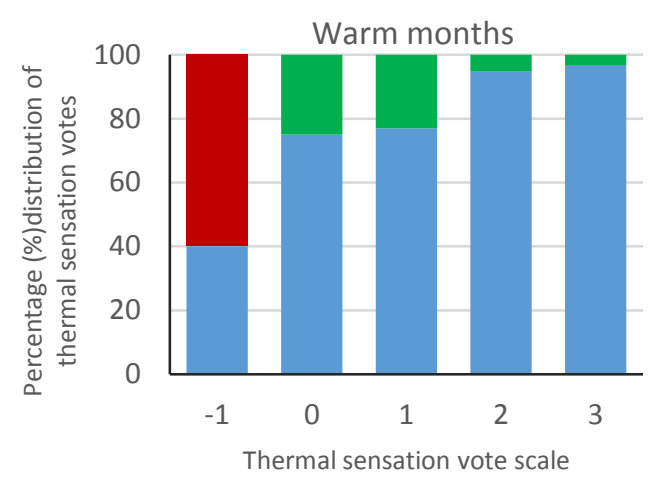

(c)

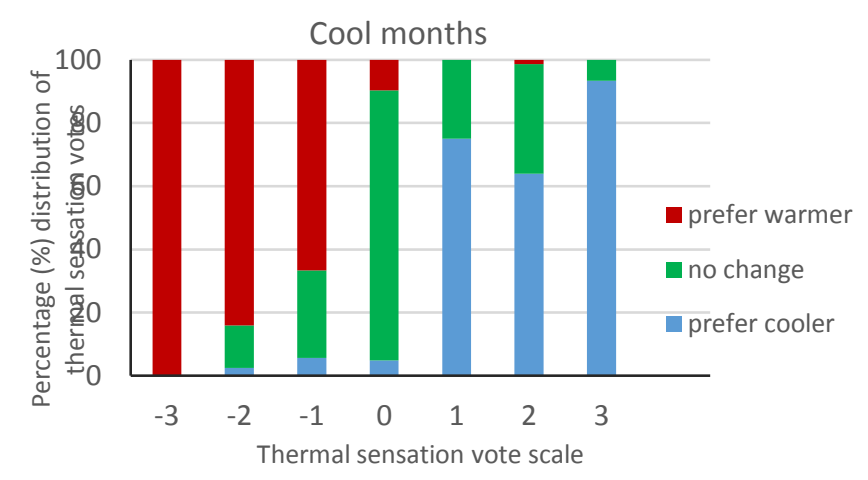

(d)

Fig 8 Percentage distribution of the variable 'ATSV' concerning the 'thermal discomfort' votes of the variable 'how do you feel at the moment?' for the warm (a) and the cool months (b). Percentage distribution of thermal preference votes of the variable 'ATSV' concerning the 'thermal discomfort' votes for the warm (c) and the cool months (d) 

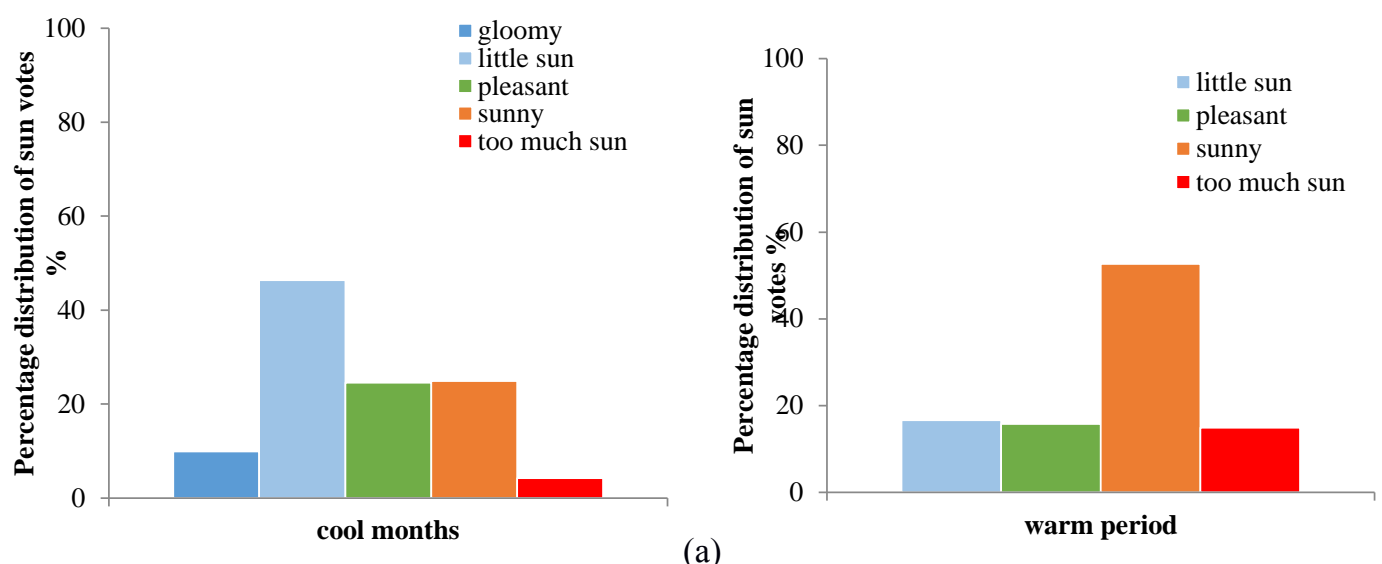

(a)

(b)

Fig 9 Percentage distribution of the variable 'sun sensation' concerning the 'thermal discomfort' votes of the variable 'how do you feel at the moment?' for the warm (a) and the cool months (b)

Figure 10 presents the 'wind sensation' percentage distribution for those in thermal discomfort for the different seasons. During the warm months (fig 10a) the largest percentage of votes concentrates in the 'little wind' category, which is $47.4 \%$, while the 'pleasant' wind category accounts for $28.0 \%$, indicating the desire for the cooling effect of wind during the summer. Regarding the cool months (fig 10b), there is not a clear trend for the 'wind sensation' distribution since the four of the five categories of wind concentrate a similar percentage of votes.
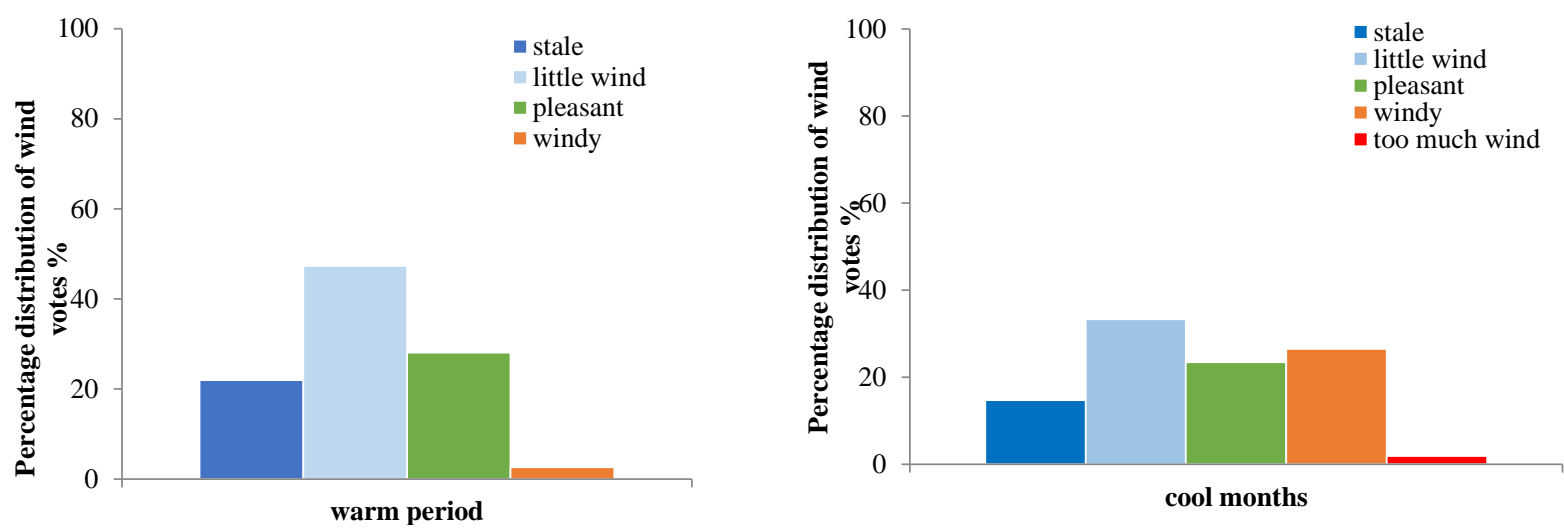

(a)

(b)

Fig 10 Percentage distribution of the variable 'wind' concerning the 'thermal discomfort' votes of the variable 'how do you feel at the moment?' for the warm (a) and the cool months (b)

\section{Use of outdoor space}

To enable microclimate and thermal comfort to be considered at the design of outdoor urban areas, it is important to evaluate whether the environmental conditions in the study areas influence their usage. Figure 11 illustrates the frequency distribution for interviewees' actual thermal sensation votes for the warm and the cool months. 
During the cool months the majority of people were found outdoors voted the 'neither cool nor warm' category of ATSV and it is interesting to note that this thermal sensation category gathers more than double amount of the interviewees' votes compared with those of the 'slightly cool' and the 'slightly warm' categories. This implies that people enjoy the environmental conditions that occur during the cool months. It is worth mentioning that for the cool months, the number of votes that correspond to ATSV: +2 is greater than the number of votes that correspond to ATSV: -2 (ATSV: $+2=225$ votes; ATSV: $-2=146$ votes), implying that the environmental conditions occur during these months are quite mild. For the warm months the majority of interviewees' actual thermal sensation votes were recorded in the 'slightly warm' category and then followed the 'neither cool nor warm' category. The fact that the majority of people were found outdoors in higher temperatures when the majority of ATSVs was +1 , suggests that people enjoy feeling warm. The small number of votes that gather the extreme ATSV categories ($3)$ and (+3) during the two seasonal periods might be explained due to thermal adaptation of citizens to the climatic conditions. For instance, during some extreme weather conditions that occurred during the cool months, although the number of visitors was significantly lower, the few interviewees did not vote for the extreme -3 ATSV category, as it would be expected, and they claimed they enjoyed the cold weather.

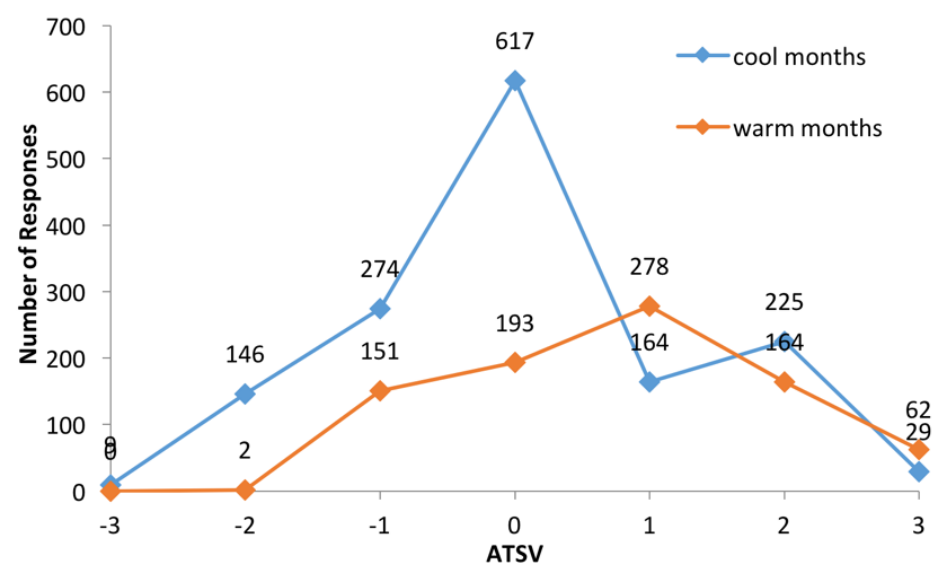

Fig 11 Frequency distribution for interviewees' actual thermal sensation votes for the warm and the cool months

The total number of interviewees found outdoors in the three examined areas is also examined for each degree of air temperature (Figure 12) for the different seasons. This figure is used as a proxy for use and the investigated sites are presented as a whole.

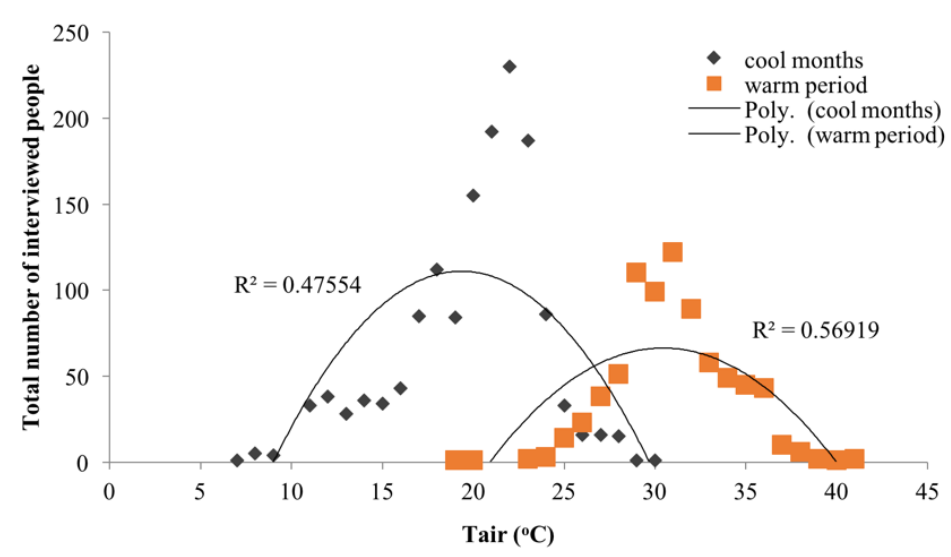

Fig 12 Number of interviewees, exploited as a proxy for use of space outdoors for each degree of air temperature for the warm and the cool months for the three examined areas 
With a coefficient of determination $\left(\mathrm{R}^{2}\right)$ on the order of 0.50 for both seasons $\left(\mathrm{R}^{2}=0.57\right.$ for the warm months and $\mathrm{R}^{2}=0.48$ for the cool period), $50 \%$ of the people found outdoors can be attributed to air temperature. With increasing air temperature the number of people in the study areas increases, reaching a critical air temperature value and then gradually decreases. This critical value is differentiated between the two seasons; the peak temperature shows a $10.0^{\circ} \mathrm{C}$ deviation between the two seasons, at $30.5^{\circ} \mathrm{C}$ for the warm months and $19.5^{\circ} \mathrm{C}$ for the cool months. This is in agreement with previous analysis (Tseliou et al. 2015), which defined the acceptable air temperature conditions for Athens, $26.0-32.0{ }^{\circ} \mathrm{C}$ for the warm and $17.0-21.0{ }^{\circ} \mathrm{C}$ cool months, with the optimum values close to the temperature where the highest number of people is found outdoors. This suggests a $10^{\circ} \mathrm{C}$ displacement of the comfort zone between the two seasons, which can be attributed to adaptation and is in agreement with previous studies in the Mediterranean climatic context (Nikolopoulou et al., 2006; Nikolopoulou, 2011)

\section{Expectations in thermal environment}

In the context of psychological adaptation, 'expectation' of the acceptable air temperature becomes important for thermal satisfaction. The analysis of thermal preferences showed that during the cool months $74.0 \%$ are satisfied with the environmental conditions whereas $18.0 \%$ prefer warmer conditions. During the warm months fewer people are satisfied, $48.0 \%$, when compared to the cool months, while $49.0 \%$ prefer cooler conditions.

Table 2. Percentage distribution of preference votes for each ATSV category, for the warm and cool months

\begin{tabular}{|l|l|l|l|l|l|l|l|}
\hline \multicolumn{4}{|c|}{ Warm months } & \multicolumn{5}{l|}{ Cool months } \\
\hline ATSV & \multicolumn{2}{|l|}{ Thermal preference (\%) } & \multicolumn{2}{l|}{ ATSV } & \multicolumn{2}{l|}{ Thermal preference (\%) } \\
\hline & $\mathbf{- 1}$ & $\mathbf{0}$ & $\mathbf{1}$ & & $\mathbf{- 1}$ & $\mathbf{0}$ & $\mathbf{1}$ \\
\hline $\mathbf{- 3}$ & - & - & - & $\mathbf{- 3}$ & - & - & 100 \\
\hline $\mathbf{- 2}$ & - & - & - & $\mathbf{- 2}$ & 2.1 & 27.4 & 71 \\
\hline $\mathbf{- 1}$ & 13.9 & 81.5 & 4.6 & $\mathbf{- 1}$ & 2.2 & 62.8 & 35 \\
\hline $\mathbf{0}$ & 25.9 & 70.5 & 3.6 & $\mathbf{0}$ & 1.6 & 92.9 & 5.5 \\
\hline $\mathbf{1}$ & 59.0 & 38.5 & 2.5 & $\mathbf{1}$ & 8.5 & 81.7 & 9.8 \\
\hline $\mathbf{2}$ & 77.9 & 22.1 & - & $\mathbf{2}$ & 32.1 & 67 & 0.9 \\
\hline $\mathbf{3}$ & 90.3 & 9.7 & - & $\mathbf{3}$ & 72.4 & 27.6 & - \\
\hline
\end{tabular}

For each ATSV category Table 2 presents the percentage distribution of thermal preference for both seasons. For the cool months $92.9 \%$ of 'neither cool nor warm' category vote for 'No change'. The percentage of 'slightly warm' (81.7\%) and 'slightly cool' (62.8\%) categories who vote 'No change' is also high. Interestingly, $67.0 \%$ of the people that have voted for the 'hot' category of ATSV have reported 'No change' during the cool months. This appears to demonstrate that individuals acknowledge the hot conditions, despite not preferring cooler ones. On the other hand, during the warm months it is clear that as we move to warmer ATSV categories the percentage of the 'Prefer cooler' votes increases, although for $81.5 \%$ of the 'slightly cool' category of ATSV votes people have voted for 'No change'. In summary, thermal neutrality does not appear to be the preferred thermal state for satisfaction, with a degree of environmental stimulation being desirable, another characteristic of psychological adaptation (Nikolopoulou, 2011). 


\section{Thermal sensation zones}

In this step, the range of each thermal sensation category was defined for the warm and cool the months under the combined influence of the average values of air temperature (Tair), solar radiation (Sol. Rad), relative humidity (RH) and wind speed (WSP). For this purpose, the logistic regression analysis was applied. This method was used previously in the works of Nikolopoulou and Lykoudis (2006) and Tseliou et al. (2015). For more details on the method the reader should refer to tseliou et al 2015 who applied the method to microclimatic and survey data on a yearly basis. In this study, the method is applied on a seasonal basis. . The four meteorological parameters were considered as the 'quantitative factors' and each thermal sensation zone was considered as the 'dependent variable' of the regression model. The categories of ATSV, 'very hot' (3) and 'very cold' (-3) were excluded from the evaluation since they were found to present statistical insignificance due to limited number of votes in these categories. The transition curves depicting ATSV zones for the warm and cool months are presented in figure 12. The code-number shown between the two transition curves corresponds to the ATSV zone with the same codenumber. More over, the temperature value ranges and the $P$-values of the residuals for each category of ATSV, for the both periods are presented in table 3 .

The average solar radiation, relative humidity and wind speed, for the warm months is $229.0 \mathrm{~W} . \mathrm{m}^{-2}, 33.0 \%$ and $0.6 \mathrm{~m} . \mathrm{s}^{-1}$, respectively (figure $\left.13 \mathrm{a}\right)$. The rather low average value of solar radiation $\left(229.0 \mathrm{~W} \cdot \mathrm{m}^{-2}\right)$, which is not typical for the climatic conditions of Athens, during the warm months is due to the evening measurements $(17: 00$ - 20:30 LST) that were conducted. It was decided to keep this value, instead of excluding the evening measurements, to ensure more representative estimation of the thermal sensation. The thermal comfort zone is as wide as $12.6{ }^{\circ} \mathrm{C}\left(16.9^{\circ} \mathrm{C}-29.5^{\circ} \mathrm{C}\right)$. Neutral temperature is $23.2{ }^{\circ} \mathrm{C}$, calculated to be at the central of thermal comfort range (Table 3$)$.

The 'slightly warm' zone is $29.6^{\circ} \mathrm{C}-41.7^{\circ} \mathrm{C}$. 'Slightly cool' zone has disappeared and has been overlaid by the 'cold' zone, since the air temperature has a $0.0^{\circ} \mathrm{C}$ range at $16.8^{\circ} \mathrm{C}$. Results are in line with previous research work (Tseliou et al. 2015), which revealed that individuals present less tolerance in low air temperature values and greater tolerance in high air temperature values implyingpotential for acclimatization to warmer environmental conditions. This finding is in line with previous studies in thermal physiology (Nikolopoulou 2011). In a previous study where the combined impact of air temperature, solar radiation, relative humidity and wind speed was examined annually, the 'slightly cool' zone presented a narrow temperature range, about $5.7{ }^{\circ} \mathrm{C}$, varying between $11.2^{\circ} \mathrm{C}$ and $16.9^{\circ} \mathrm{C}$ (Tseliou et al. 2015).

Among P-values, only the P-values of the 'neither cool nor warm' category present statistical significance implying that more factors seem to affect this zone of ATSV. 


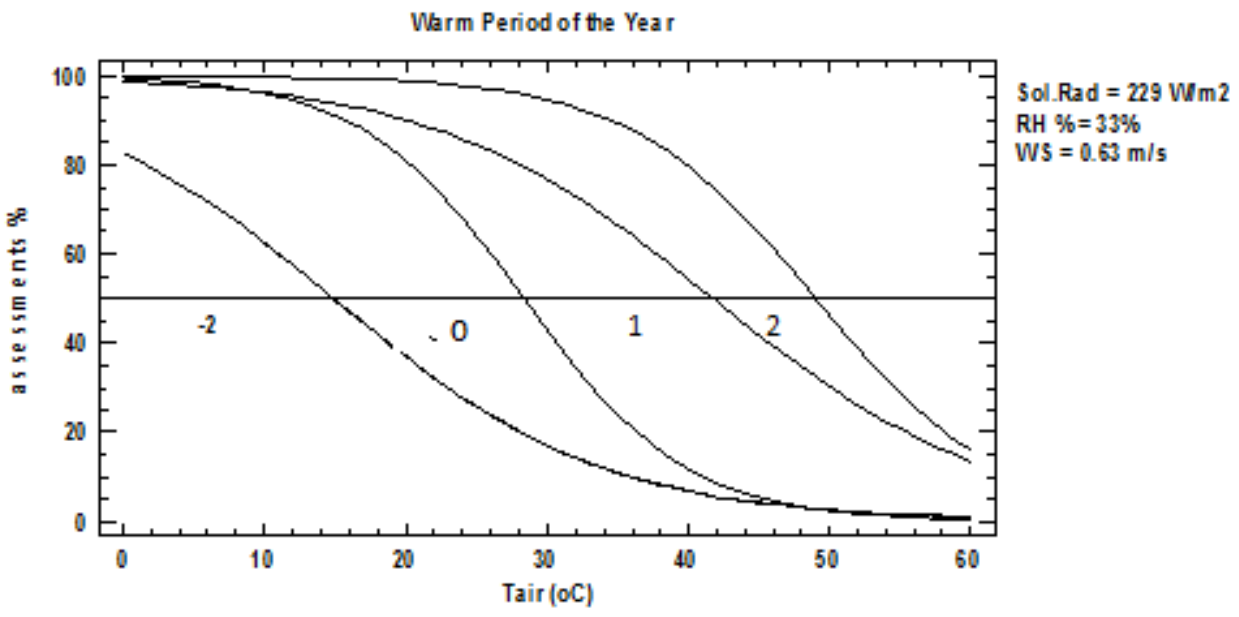

(a)

Cool months of the year

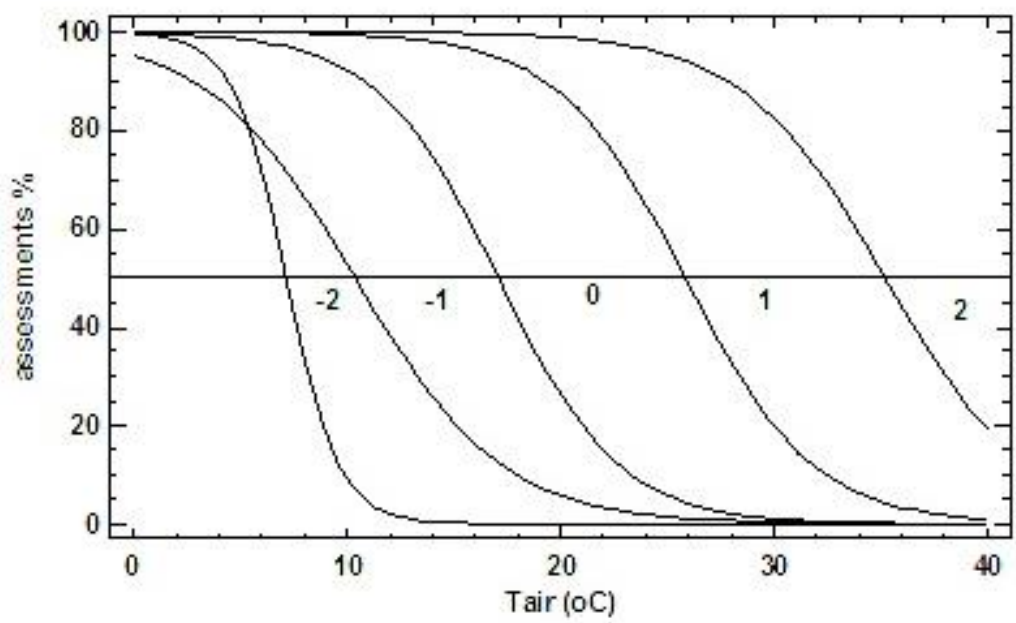

Sol. $\mathrm{Rad}=428 \mathrm{~W} / \mathrm{m} 2$

$\mathrm{RH} \%=48$

WS $=0.70 \mathrm{mis}$

(b)

Fig 13 ATSV zones during the warm (a) and the cool months (b). Parameters: air temperature, Tair $\left({ }^{\circ} \mathrm{C}\right), \mathrm{RH}(\%)$, wind speed $\left(\mathrm{m} . \mathrm{s}^{-1}\right)$, solar radiation $\left(\mathrm{W} \cdot \mathrm{m}^{-2}\right)$. Actual Thermal sensation scale: cold $(-2)$, slightly cool $(-1)$, neither cool nor warm (0), slightly warm (1), hot (2).

Table 3 Actual thermal sensation zones during the warm and the cool months under the combined effect of air temperature (Tair), wind speed (WS), solar radiation (Sol.rad) and RH

\begin{tabular}{|l|l|l|l|l|}
\hline & \multicolumn{2}{|l|}{ Warm months } & \multicolumn{2}{l|}{ Cool months } \\
\hline ATSV zones & $\begin{array}{l}\text { Tair range } \\
\left({ }^{\circ} \mathrm{C}\right)\end{array}$ & $\begin{array}{l}\text { P-VALUES } \\
\text { Residual }\end{array}$ & $\begin{array}{l}\mathbf{T}_{\text {air }} \text { range } \\
\left({ }^{\circ} \mathrm{C}\right)\end{array}$ & $\begin{array}{l}\text { P-VALUES } \\
\text { Residual }\end{array}$ \\
\hline Cold (-2) & $<16.8$ & 1.0 & $<\mathbf{1 0 . 3}$ & 1.0 \\
\hline Slightly cool (-1) & $\mathbf{1 6 . 8 - 1 6 . 8}$ & 0.9 & $\mathbf{1 0 . 4}-\mathbf{1 7 . 1}$ & 0.8 \\
\hline Neither cool nor warm (0) & $\mathbf{1 6 . 9 - 2 9 . 5}$ & 0.0 & $\mathbf{1 7 . 2}-\mathbf{2 5 . 7}$ & 0.0 \\
\hline Slightly warm (1) & $\mathbf{2 9 . 6 - 4 1 . 7}$ & 1.0 & $\mathbf{2 5 . 8}-\mathbf{3 5 . 2}$ & 1.0 \\
\hline Hot (2) & $\mathbf{> 4 1 . 7}$ & 1.0 & $\mathbf{> 3 5 . 2}$ & 1.0 \\
\hline
\end{tabular}


As far as the cool months are concerned, the average value of solar radiation, relative humidity and wind speed is $428.0 \mathrm{~W} \cdot \mathrm{m}^{-2}, 48.0 \% \mathrm{\kappa} \alpha \mathbf{1} 0.7 \mathrm{~m} . \mathrm{s}^{-1}$, respectively (figure $13 \mathrm{~b}$ ). The thermal comfort zone is $8.5^{\circ} \mathrm{C}$ wide and fluctuates between $17.2^{\circ} \mathrm{C}$ and $25.7^{\circ} \mathrm{C}$. Neutral temperature is found to be at the central of the zone at $21.4^{\circ} \mathrm{C}$ (Table 3). The 'slightly warm' category fluctuates between $25.8^{\circ} \mathrm{C}$ and $35.2^{\circ} \mathrm{C}$ and the 'slightly cool' category presents a range of $6.7^{\circ} \mathrm{C}$, ranging from $10.4^{\circ} \mathrm{C}$ to $17.1^{\circ} \mathrm{C}$.

\section{ATSV, microclimatic parameters and PET index estimations}

The next step in the present study is to examine the relationship among the actual thermal sensation votes and the air temperature, wind speed, mean radiant temperature and the bioclimatic index Physiological Equivalent Temperature (PET) for both the warm and the cool months of the year. Mean actual thermal sensation votes (mATSV) were calculated and plotted against the measured variables air temperature $\left(\right.$ Tair ${ }^{\circ} \mathrm{C}$ ), wind speed (WSP $\mathrm{m} \cdot \mathrm{s}^{-1}$ ), mean radiant temperature $\left(\mathrm{Tmrt}^{\circ} \mathrm{C}\right)$ and PET. In the case of the air temperature, mean radiant temperature and PET, the ATSV values were averaged for each $1.0^{\circ} \mathrm{C}$ bin whereas in the case of wind speed the ATSV values were averaged for each $0.1 \mathrm{~m} \cdot \mathrm{s}^{-1}$ bin.

Figure 14 illustrates the relationship between air temperature and thermal sensation with corresponding regression lines for the warm and the cool months. The term 'Neutral Temperature' is often used to describe thermal comfort and considered to be in the central 'neither cool nor warm' category (ATSV=0), where people are considered to be in a state of neutrality. Then, based on the linear regression models (Fig 14), the neutral temperature for the two seasonal periods is calculated by setting $\mathrm{y}=\mathrm{mATSV}=0$. It is found that the neutral temperature differentiates from $25.7^{\circ} \mathrm{C}$ during the warm months to $19.5^{\circ} \mathrm{C}$ during the cool months. A difference of $6.2^{\circ} \mathrm{C}$ between the neutral temperatures in the warm and cool months reveals an effect of seasonal adaptation on thermal comfort as a result of behavioral (such as clothing adjustment) and psychological adaptation (such as experience and expectations). The slopes of the changes in the thermal sensation with increased air temperature were 0.13 for the warm months and 0.17 for the cool months. Based on the linear regression models we can calculate that a slope of 0.13 means that a change to the next thermal sensation category corresponds to $7.7^{\circ} \mathrm{C}$ increase in air temperature during the warm period and a slope of 0.17 means that a change to the next thermal sensation category corresponds to $6.0^{\circ} \mathrm{C}$ during the cool months. These results reveal that changes in thermal sensation happen easier during the cool months.

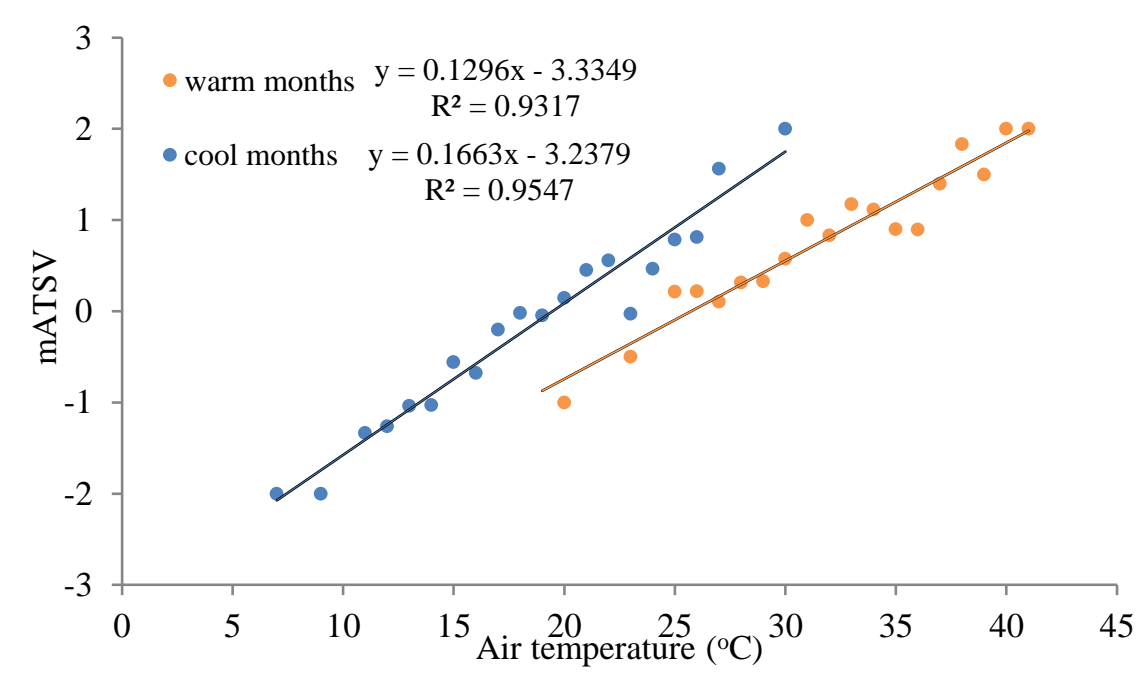

Fig 14 Relationship between mean thermal sensation and air temperature for the warm and the cool months 
Figure 15 illustrates the relationship between mATSV and the wind speed for the warm and the cool months. The low coefficient of determination $\left(\mathrm{R}^{2}\right)$ for the two seasonal periods indicates that wind speed plays a secondary role in terms of thermal sensation in the case of Athens. Indeed, less than $20 \%$ of the changes in thermal sensation categories could be explained by changes in wind speed in both the warm $\left(R^{2}: 0.08\right)$ and the cool months $\left(R^{2}\right.$ : 0.16). However, it is important to note that the average wind speed that was recorded during the field surveys was $0.6 \mathrm{~m} . \mathrm{s}^{-1}$ for the warm months and $0.7 \mathrm{~m} . \mathrm{s}^{-1}$ for the cool months, which it could be characterized quite mild to cause important changes in thermal sensation. However, based on this evidence, we could note that the same wind speed affects thermal sensation more during the cool months, highlighting the sensitivity to lower air temperatures and colder conditions.

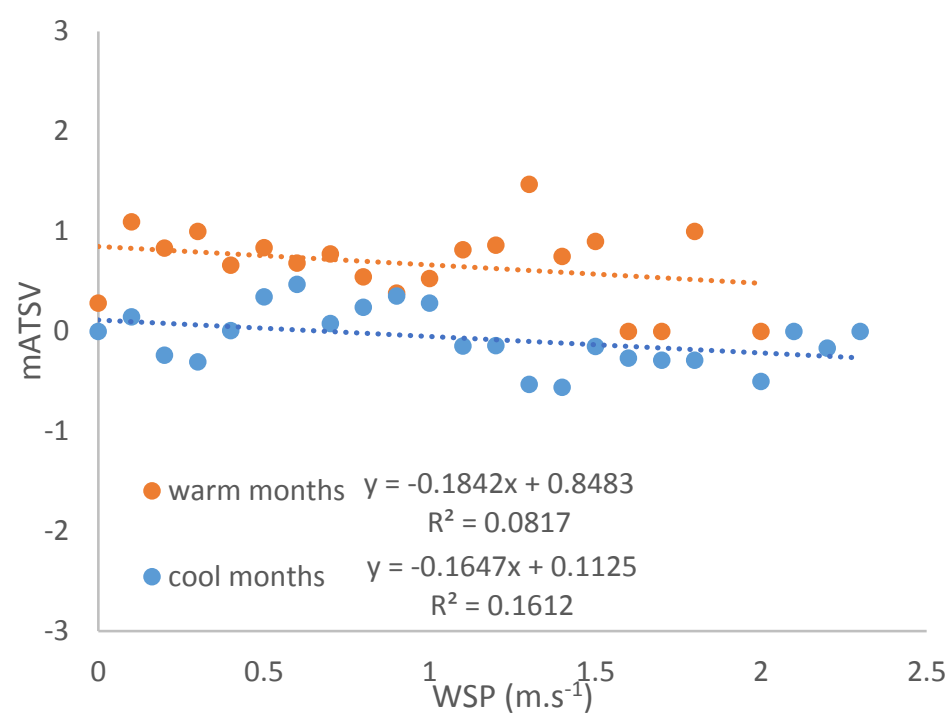

Fig 15 Relationship between mean thermal sensation and wind speed (WSP $\mathrm{m} \cdot \mathrm{s}^{-1}$ ) for the warm and the cool months

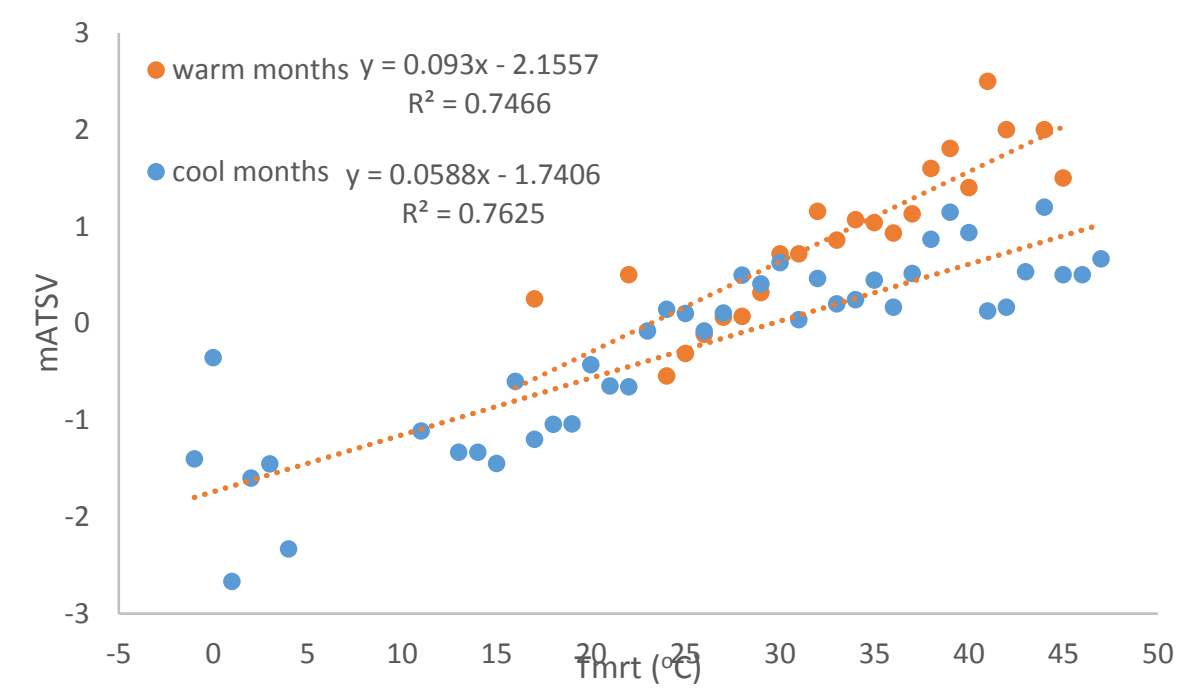

Fig 16 Relationship between mean thermal sensation and the mean radiant temperature $\left(\operatorname{Tmrt}^{\circ} \mathrm{C}\right)$ for the warm and the cool months 
Mean Radiant Temperature presents the same trend for the warm and the cool months and it is another important parameter that affects thermal sensation as illustrated in figure 16. Both the warm and the cool months present the same value of coefficient of determination (warm months $\mathrm{R}^{2}: 0.75$, cool months $\mathrm{R}^{2}: 0.76$ ) which explains the $76 \%$ of the changes in thermal sensation. The slopes of the changes in the thermal sensation with increased mean radiant temperature were 0.09 for the warm months and 0.06 for the cool months. Based on the linear regression models we can calculate that a slope of 0.09 implies that a change to the next thermal sensation category corresponds to a $10.8^{\circ} \mathrm{C}$ change in mean radiant temperature during the warm months, while a slope of 0.06 means that a change to the next thermal sensation category corresponds to a $17.0^{\circ} \mathrm{C}$ change in mean radiant temperature during cool months. These results reveal that, as opposed to air temperature, in the case of mean radiant temperature changes in thermal sensation happen easier during the warm months.

The bioclimatic index PET was also applied to predict the interviewees' thermal sensation and to be compared with the actual thermal sensation votes (Figure 17). Results show that ATSV presents stronger correlation with the PET index during the warm months where the determination coefficient is 0.94 . The correlation between PET and ATSV appears to be strong for the cool months as well where the $\mathrm{R}^{2}$ is 0.83 . The neutral PET temperature for both the warm and the cool months was also calculated following the same method used above for the determination of the neutral air temperature. For the warm months, by setting ATSV=0 in the fitted regression line the PET value in which people feel neutral is $26.5^{\circ} \mathrm{C}$, which is almost $3.5^{\circ} \mathrm{C}$ higher comparing with the conventional PET scale where the neutral zones varies between $18-23{ }^{\circ} \mathrm{C}$. For the cool months, the neutral PET temperature is found to be $19.4{ }^{\circ} \mathrm{C}$ which it is included in the neutral zone of the conventional PET scale. These findings reveal that the PET value that people feel neutral differs between the warm and the cool months of the year. Moreover, the results of the present study are in line with previous research work of Tseliou and Tsiros (2016) who modified the initial PET scale and developed two seasonal PET scales according to the climatic characteristics of the Mediterranean region. According to their research, during the warm period the acceptable environmental range for PET ranges between $26.0-34.0\left({ }^{\circ} \mathrm{C}\right)$ and $19.0-25.0\left({ }^{\circ} \mathrm{C}\right)$ during the cool period.

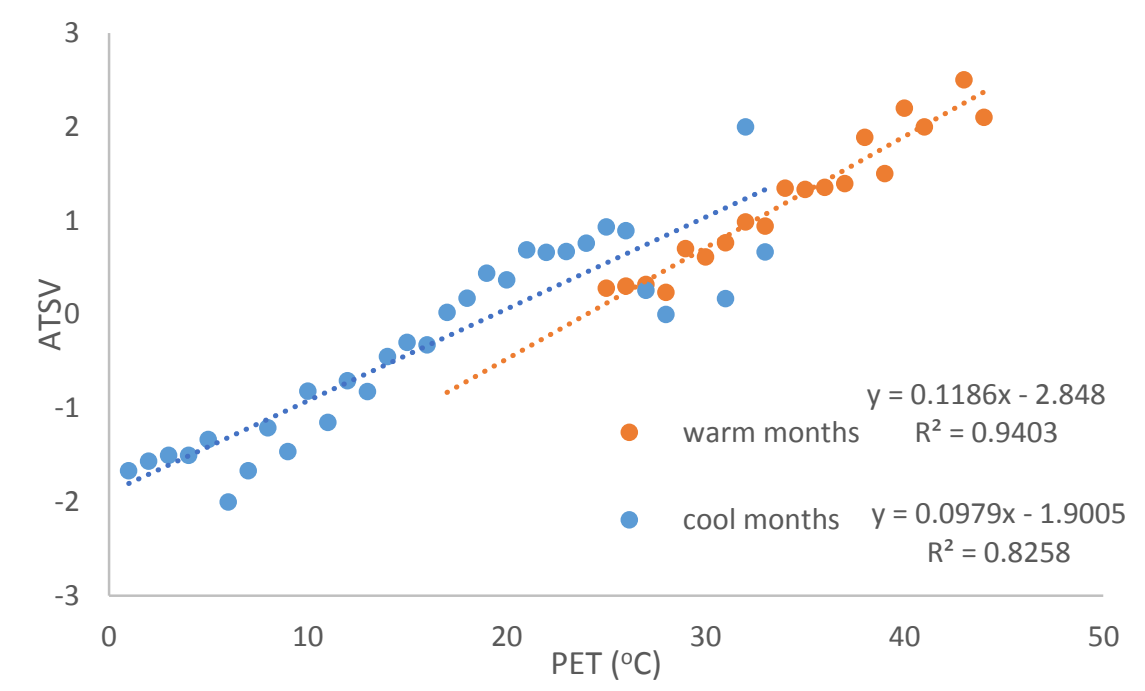

Fig 17 Relationship between mean thermal sensation and PET for the warm and the cool months

\section{Concluding remarks and implications}


The analysis for Athens, a city with Mediterranean climate, highlighted that the vast majority of individuals are in 'thermal comfort' for both the warm (86.6\%) and cool (82.4\%) season, despite the average difference in air temperature of more than $10.0^{\circ} \mathrm{C}$, suggesting that individuals are well adapted in their thermal environment. This finding is in agreement with previous research work of Nikolopoulou and Lykoudis (2006) who revealed that the levels of overall comfort were very high for the 14 European cities investigated, demonstrating that in the vast majority people is satisfied with the environment since overall comfort on an annual basis was over $75 \%$ for all cities.

Comparing thermal neutrality between the two seasons, as a proxy for thermal comfort, the highest percentage of votes in the 'neither cool nor warm' category (ATSV $=0)$ is observed during the cool months $(42.0 \%)$ which also constitutes the category of ATSV that gathers the majority of votes among the other ATSV categories during the cool months. This also influences people's attendance in the outdoor urban areas, which is bigger during the cool months when the majority of the thermal sensation responses are for the 'neither cool nor warm' category of ATSV. This suggests that despite the wide adaptive capacity, the most pleasant environmental conditions occur during the cool months where the average air temperature, solar radiation and wind speed vary at around $15^{\circ} \mathrm{C}, 400 \mathrm{Wm}^{-2}$ and $0.7 \mathrm{~m} . \mathrm{s}^{-1}$, respectively. This is in agreement with previous work in similar climatic contexts. For example Spagnolo and De dear (2003) also found a similar difference in distribution between seasons in Sydney, while Yahia and Johansson (2012) showed that the highest percentage of people feeling comfortable in Damascus was during winter.

As far as the warm months in concerned, the category of ATSV that gathers the majority of votes is 'slightly warm' (ATSV $=1: 32.0 \%$ ) while the 'neither warm nor cool category' accounts for $27.0 \%$ of the votes. warm months. The combination of 'hot' (ATSV = 2: 50.0\%) and very hot conditions (ATSV=3:27.0\%), strong sun (sun sensation =1: $53.0 \%$ ) and little wind (wind sensation=-1: 47.0\%) are strongly related with the 'thermal discomfort' votes.

Focusing on the total number of "thermal discomfort" votes during the cool months, the only clear trend towards concentration of votes is the sun variable, where the $46.0 \%$ of interviewees voted "little sun".

The use of space appears to be strongly dependent on the outdoor conditions, as the number of people increases with the air temperature increase until a critical value which is different between the two periods that is $30.5^{\circ} \mathrm{C}$ the warm months and $19.5^{\circ} \mathrm{C}$ the cool months. People's adaptive capacity and the effect of experience and expectations is partly responsible for the deviation of this critical value which is more than $10.0{ }^{\circ} \mathrm{C}$ between the seasons.

Regarding 'thermal preference' $74.0 \%$ of the participants are satisfied with the air temperature during the cool months whereas for the warm months this is $48.0 \%$, in agreement with previous findings of the present study that imply that participants are more satisfied with the environmental conditions during the cool months.

The examination of the thermal sensation categories under the combined influence of four meteorological parameters showed that only the 'neither cool nor warm zone of ATSV presents statistical insignificance in the $P$ values of residuals in both the warm and the cool months This finding suggests that apart from the neutral category of ATSV, the examined parameters are adequate to predict the other thermal sensation zones. In the case of the 'neither cool nor warm' category the finding implies that other factor should also be taken into consideration such as adaptation and other personal parameters. This result is in agreement with previous findings of Tseliou et al. (2015) who examined the thermal sensation zones under the combined effect of the same four meteorological 
parameters, annually. The neutral temperature is estimated to be $23.2{ }^{\circ} \mathrm{C}$ for the warm months and $21.4^{\circ} \mathrm{C}$ for the cool months. This difference in neutral temperatures between seasons has also been founded for other European cities (Nikolopoulou and Lykoudis 2006). The neutral temperatures appear to follow the profile of the respective climatic temperatures on a seasonal basis, hence, as climatic air temperature increases, the closer neutral temperature is to it (Nikolopoulou 2011).

The analysis of the relationship between thermal sensation and air temperature, wind speed, mean radiant temperature and PET showed that the same trend is apparent, where each examined parameter appears to affect thermal sensation in almost the same level as compared to the two seasonal periods. The strongest correlation was observed between ATSV and Tair (warm months: $\mathrm{R}^{2}=0.93$, cool months $\mathrm{R}^{2}=0.95$ ) and the weakest between ATSV and wind speed. Regarding Tair the neutral temperature for Athens Mediterranean climate was calculated to be $25.7{ }^{\circ} \mathrm{C}$ for the warm months and differentiates to $19.5^{\circ} \mathrm{C}$ during the cool months. Similarly, the neutral PET temperature is found to be $26.5^{\circ} \mathrm{C}$ for the warm months and $19.4^{\circ} \mathrm{C}$ for the cool months. Such difference of people's thermal sensation between the seasons demonstrates adaptation taking place.

In terms of implications for urban design, findings such as the ones presented in this study may provide some useful information for designers to identify priorities for the development of urban areas. In the case of Athens, undoubtedly, adaptation plays an important role in extending the comfort zones at different seasons, priority should be given to the warm months of the year to prevent overheating and enhance cooling. As an example, regarding the vegetation, dense deciduous trees should be preferred in order to offer shade and protection from the strong solar radiation during the warm months, but also let sunlight during the cool months. However, the presence of evergreen trees is also necessary since there is enough sunlight during the cool months, making access to shade occasionally desirable. Despite the fact that the average wind speed is quite low both during the summer and the winter, appropriate installation of the trees from the urban designers could improve the ventilation especially during the warm period or reversely provide protection in the cooler period. Improving the thermal comfort conditions in the urban spaces by applying the knowledge acquired regarding the thermal preferences of citizens may contribute to the sustainable development of cities by reducing energy consumption and energy demands and at the same time improving the social and cultural lifestyle by helping people come close to nature.

\section{Acknowledgments}

The authors thank the four reviewers for their comments and helpful suggestions

\section{References}

Ahmed KS (2003) Comfort in urban spaces: Defining the boundaries of outdoor thermal comfort for the tropical urban environments. Energy and Buildings 35: 103-110.

Ali-Toudert F, Mayer H (2006) Numerical study on the effects of aspect ratio and orientation of an urban street canyon on outdoor thermal comfort in hot and dry climate. Building and Environment 41: 94108.

ASHRAE (1966) Thermal comfort conditions. ASHRAE Standards. ASHRAE, New York, pp 55-66

Ballantyne ER, Hill RK, Spencer JW (1977) Probit analysis of thermal sensation assessments. International Journal of Biometeorology 21(1) 
Charalampopoulos I, Tsiros I, Chronopoulou A, Matzarakis A (2014) A Note on the Evolution of the Daily Pattern of Thermal Comfort-Related Micrometeorological Parameters in Small Urban Sites in Athens. International Journal of Biometeorology.

Charalampopoulos I, Tsiros I, Matzarakis A, Chronopoulou A (2012) Analysis of the Thermal Bioclimate in Various Urban Configurations in Athens, Greece. Urban Ecosystems 16 (2): 217-233

Cheng V, Ng E (2006) Thermal comfort in urban open spaces for Hong Kong. Architectural Science Review 49(3): 236-242

Chen L, Ng E (2012) Outdoor thermal comfort and outdoor activities: a review of research in the past decade. Cities 29:118-125

Cheng V, Ng E, Chan C, Givoni B (2012) Outdoor thermal comfort study in sub-tropical climate: A longitudinal study based in Hong Kong. International Journal of Biometeorology 56 (1): 43-56

Declet-Barreto J, Brazel A J, Martin CA, Chow, W. T., \& Harlan, S. L. (2013). Creating the park cool island in an inner-city neighborhood: heat mitigation strategy for Phoenix, AZ. Urban Ecosystems, 16(3), $617-$ 635

Emmanuel R, Rosenlund H, Johansson E (2007) Urban shading - a design option for the tropics? A study in Colombo, Sri Lanka. Int J Climatol 27: 1995 - 2004

Fanger PO 1970 Thermal Cofort. Copenhagen: Danish Technical Press.

Fanger PO (1973) Assessment of man's thermal comfort in practice. British journal of industrial medicine, 30(4), 313-324

Hoppe P (1984) Die Energiebilanz des Menschen. University of Munich. (in German)

Hoppe P (1993) Heat balance modelling. Experientia, 49: 741-746

Hoppe P (1999). The physiological equivalent temperature-A universal index for the biometeorological assessment of the thermal environment. International Journal of Biometeorology, 43: 71-75.

Johansson E, Yahia MW (2011) Subjective Thermal Comfort in Urban Spaces in the Warm-humid City of Guayaquil, Ecuador. PLEA 2011 - 27th Conference on Passive and Low Energy Architecture, Louvainla- Neuve, Belgium, 13-15 July

Kántor N, and Unger J (2010) Benefits and opportunities of adopting GIS in thermal comfort studies in resting places: an urban park as an example. Landscape and Urban Planning 98(1): 36-46

Kántor N, Kovács A, Takács Á (2016) Seasonal differences in the subjective assessment of outdoor thermal conditions and the impact of analysis techniques on the obtained results. International journal of biometeorology, 1-21

Knez I, Thorsson S (2006) Influences of Culture and Environmental Attitude on Thermal, Emotional and Perceptual Evaluations of a Public Square. Int J Biometeorol 50: 258-268

Krüger E, Drach P, Emmanuel R, Corbella O (2013) Assessment of daytimeoutdoor comfort levels in and outside the urban area of Glasgow, UK. Int. J.Biometeorol. 57: 521-533 
Lenzholzer S (2010) Engrained experience - a comparison of microclimate perception schemata and microclimate measurements in Dutch urban squares. International journal of biometeorology 54(2): 141-150

Lin TP (2009) Thermal Perception, Adaptation and Attendance in Public Square in Hot and Humid Regions. Building and Environment 44: 2017-2026

Matzarakis A, Mayer H (1997) Heat stress in Greece. International Journal of Biometeorology, 41: 34-39

Matzarakis A, Mayer H, Iziomon MG (1999) Applications of a universal thermal index: Physiological equivalent temperature. International Journal of Biometeorology, 43: 76-84

Matzarakis A, Mayer H (2000). Atmospheric conditions and human thermal comfort in urban areas. In: Proceeings of 11th Seminar on Environmental Protection Environment and Health, Thessaloniki, Greece, pp. 155166

Matzarakis A (2000) Assessing climate for tourism purposes: Existing methods and tools for the thermal complex. University of Freiburg

Matzarakis A, Rutz F, Mayer H (2007) Modeling radiation fluxes in simple and complex environments-Application of the RayMan model. International Journal of Biometeorology, 51: 323-334

Matzarakis A, Rutz F, Mayer H (2010). Modelling radiation fluxes in simple and complex environments-Basics of the RayMan model. International Journal of Biometeorology, 54: 131-139

Mayer H, Hoppe P (1987) Thermal comfort of man in different urban environments. Theoretical and Applied Climatology, 38: 43-49

Nastos PT, Matzarakis A (2013) Human Bioclimatic Conditions, Trends, and Variability in the Athens University Campus, Greece. Advances in Meteorology 2013:8

Nikolopoulou M, Baker N and Steemers K (1999) Improvements to the globe thermometer for outdoor use. Architectural Science Review 42(1): 27-34

Nikolopoulou M, Baker N, Steemers K (1999b) Thermal comfort in urban spaces: different forms of adaptation. Proceedings of the REBUILD 1999 on Shaping Our Cities for the 21st Century, Barcelona

Nikolopoulou M, and Steemers K (2003) Thermal Comfort and Psychological Adaptation as a Guide for Designing Urban Spaces. Energy and Buildings 35: 95-101

Nikolopoulou M and Lykoudis S (2006) Thermal comfort in outdoor urban spaces: Analysis across different European countries. Building and Environment, 41(11), 1455-1470

Nikolopoulou M, Lykoudis S (2007) Use of Outdoor Spaces and Microclimate in a Mediterranean Urban Area. Building and Environment 42: 3691-3707

Nikolopoulou M. (2011) Outdoor thermal comfort. Frontiers in Bioscience, 3, 1552-1568

Oliveira S and Andrade H (2007) An initial assessment of the bioclimatic comfort in an outdoor public space in Lisbon, Int. J. Biometeorol. 52: 69-84, http://dx.doi.org/10.1007/s00484-007-0100-0

Pantavou K, Theoharatos G, Santamouris M, Asimakopoulos D (2013) Outdoor thermal sensation of pedestrians in a Mediterranean climate and a comparison with UTCI. Build Environ 66: 82-95

Parsons KC (2003) Human thermal environments: the effects of hot, moderate and cold environments on human health, comfort and performance, 2nd edn. Taylor and Francis, New York

Pearlmutter D, Jiao D, Garb Y (2014) The relationship between bioclimatic thermal stress and subjective thermal sensation in pedestrian spaces. International journal of biometeorology, 58(10), 2111-2127 
Rupp RF, Vásquez NG, Lamberts R (2015): A review of human thermal comfort in the built environment. Energy and Buildings 105: 178-205

Santamouris M, Papanikolaou N, Koronakis I, Livada I, Asimakopoulos D (1999) Thermal and Air Flow Characteristics in a Deep Pedestrian Canyon Under Hot Weather Conditions. Atm Environ 33: 45034521

Spagnolo J, De Dear R (2003) A field study of thermal comfort in outdoor and semi-outdoor environments in subtropical Sydney Australia. Building and Environment 38(5): 721-738

Shashua-Bar L, Tsiros I, Hoffman ME (2012) Passive cooling design options to ameliorate thermal comfort in urban streets of a Mediterranean climate (Athens) under hot summer conditions. Building and Environment 57, 110-119

Tseliou, A., \& Tsiros, I. X. (2016) Modeling urban microclimate to ameliorate thermal sensation conditions in outdoor areas in Athens (Greece). Building Simulation, (Vol. 9, No. 3, pp. 251-267)

Tseliou A, Tsiros IX, Nikolopoulou M, Papadopoulos G (2015) Outdoor thermal sensation in a Mediterranean climate (Athens): The effect of selected microclimatic parameters. Architectural Science Review, 1-13

Tseliou A, Tsiros IX, Nikolopoulou M, Psyloglou V, Lykoudis S (2013) Aspects of human thermal preferences in the urban outdoor environment of Athens: A priliminary study. Proceedings of the 13th International Conference of Environmental Science and Technology Athens, Greece, September 5-7

Tsiros IX, Hoffman ME (2014) Thermal and Comfort Conditions in a Semi-Closed Rear Wooded Garden and its Adjacent Semi-Open Spaces in a Mediterranean Climate (Athens) During Summer. Architectural Science Review 57 (1): 63-82

Vanos JK, Warland JS, Gillespie TJ, Kenny NA (2010) Review of the physiology of human thermal comfort while exercising in urban landscapes and implications for bioclimatic design. International journal of biometeorology, 54(4), 319-334.

Yahia MW, Johansson E (2012) Evaluating the behavior of different thermal indices by investigating various outdoor urban environments in the hot dry city of Damascus, Syria. Int J Biometeorol 57 (4):615-63

Yang W, Wong NH, Jusuf SK (2013) Thermal comfort in outdoor urban spaces in Singapore. Build Environ 59: $426-435$ 
Tseliou, A., Tsiros, I.X. \& Nikolopoulou, M. Int J Biometeorol (2017). doi:10.1007/s00484-016-1298-5

\section{Table 1}




\begin{tabular}{|c|c|c|c|c|}
\hline Study areas & Seasonal period & Month & Date of field study & Diurnal \\
\hline \multirow[t]{7}{*}{ Square I } & Cool months & October & $\begin{array}{l}5.10 .10,6.10 .10 \\
20.10 .10,23.10 .10 \\
21.10 .10\end{array}$ & $10: 00-15: 00$ \\
\hline & & November & $\begin{array}{l}4.11 .10,5.11 .10 \\
8.11 .11,11.11 .10 \\
18.11 .10,27.11 .10\end{array}$ & $\begin{array}{l}10: 00-15: 00 \\
10: 00-21: 00\end{array}$ \\
\hline & & March & $\begin{array}{l}6.3 .12,13.3 .12 \\
15.3 .12,20.3 .12 \\
22.3 .12\end{array}$ & $10: 00-15: 00$ \\
\hline & Warm months & May & 9.5 .12 & $17: 30-20: 30$ \\
\hline & & June & $\begin{array}{l}11.6 .11 \\
21.6 .11\end{array}$ & $\begin{array}{l}10: 00-15: 00 \\
17: 30-20: 30\end{array}$ \\
\hline & & July & $\begin{array}{l}1.7 .11 \\
13.7 .11\end{array}$ & $\begin{array}{l}17: 30-20: 30 \\
10: 00-21: 00\end{array}$ \\
\hline & & September & 19.9.11 & $10: 00-15: 00$ \\
\hline \multirow[t]{4}{*}{ Square II } & Cool months & March & $\begin{array}{l}\text { 8.3.12, 9.3.12, } \\
16.3 .12\end{array}$ & $10: 00-15: 00$ \\
\hline & & April & 27.4 .12 & $10: 00-15: 00$ \\
\hline & Warm months & June & $\begin{array}{l}\text { 9.6.11, } \\
17.6 .11\end{array}$ & $\begin{array}{l}10: 00-15: 00 \\
17: 30-20: 30\end{array}$ \\
\hline & & July & $\begin{array}{l}\text { 6.7.11, 11.7.11 } \\
24.7 .11\end{array}$ & $\begin{array}{l}10: 00-15: 00 \\
10: 00-21: 00\end{array}$ \\
\hline \multirow[t]{7}{*}{ Park } & Cool months & October & $\begin{array}{l}8.10 .10,9.10 .10 \\
17.10 .10,24.10 .10 \text {, } \\
31.10 .10\end{array}$ & $10: 00-15: 00$ \\
\hline & & November & $\begin{array}{ll}1.11 .10 & 13.11 .10 \\
14.11 .10 & 26.11 .10 \\
20.11 .10 & \end{array}$ & $\begin{array}{l}10: 00-15: 00 \\
10: 00-21: 00\end{array}$ \\
\hline & & March & $\begin{array}{cc}10.3 .12 & 17.3 .12 \\
18.3 .12 & 31.3 .12 \\
\end{array}$ & $10: 00-15: 00$ \\
\hline & Warm months & May & 19.5.12 & $10: 00-15: 00$ \\
\hline & & June & $23.6 .11 \quad 24.6 .11$ & $10: 00-15: 00$ \\
\hline & & July & $\begin{array}{l}\text { 7.7.11, 15.7.11, } \\
\text { 19.7.11 }\end{array}$ & $\begin{array}{l}10: 00-21: 00 \\
17: 00-20: 30\end{array}$ \\
\hline & & September & $\begin{array}{l}\text { 21.9.11, 24.9.11, } \\
\text { 25.9.11 }\end{array}$ & $10: 00-15: 00$ \\
\hline
\end{tabular}


Table 2

\begin{tabular}{|c|c|c|c|c|c|c|c|}
\hline \multicolumn{3}{|c|}{ Warm months } & \multicolumn{3}{c|}{ Cool months } \\
\hline ATSV & \multicolumn{3}{|c|}{ Thermal preference } & \multicolumn{2}{c|}{ ATSV } & \multicolumn{3}{c|}{ Thermal preference } \\
& \multicolumn{3}{|c|}{$(\%)$} & & \multicolumn{3}{c|}{} \\
\hline & $\mathbf{- 1}$ & $\mathbf{0}$ & $\mathbf{1}$ & & $\mathbf{- 1}$ & $\mathbf{0}$ & $\mathbf{1}$ \\
\hline $\mathbf{- 3}$ & - & - & - & $\mathbf{- 3}$ & - & - & 100 \\
\hline $\mathbf{- 2}$ & - & - & - & $\mathbf{- 2}$ & 2.1 & 27.4 & 71 \\
\hline $\mathbf{- 1}$ & 13.9 & 81.5 & 4.6 & $\mathbf{- 1}$ & 2.2 & 62.8 & 35 \\
\hline $\mathbf{0}$ & 25.9 & 70.5 & 3.6 & $\mathbf{0}$ & 1.6 & 92.9 & 5.5 \\
\hline $\mathbf{1}$ & 59.0 & 38.5 & 2.5 & $\mathbf{1}$ & 8.5 & 81.7 & 9.8 \\
\hline $\mathbf{2}$ & 77.9 & 22.1 & - & $\mathbf{2}$ & 32.1 & 67 & 0.9 \\
\hline $\mathbf{3}$ & 90.3 & 9.7 & - & $\mathbf{3}$ & 72.4 & 27.6 & - \\
\hline
\end{tabular}


Table 3

\begin{tabular}{|l|l|l|l|l|}
\hline \multicolumn{2}{|l|}{ Warm months } & \multicolumn{2}{l|}{ Cool months } \\
\hline ATSV zones & $\begin{array}{l}\text { Tair range } \\
\left({ }^{\circ} \mathrm{C}\right)\end{array}$ & $\begin{array}{l}\text { P-VALUES } \\
\text { Residual }\end{array}$ & $\begin{array}{l}\text { Tair range } \\
\left({ }^{\circ} \mathrm{C}\right)\end{array}$ & $\begin{array}{l}\text { P-VALUES } \\
\text { Residual }\end{array}$ \\
\hline Cold (-2) & $<16.8$ & 1.0 & $<\mathbf{1 0 . 3}$ & 1.0 \\
\hline Slightly cool $(-1)$ & $\mathbf{1 6 . 8 - 1 6 . 8}$ & 0.9 & $\mathbf{1 0 . 4}-\mathbf{1 7 . 1}$ & 0.8 \\
\hline Neither cool nor warm (0) & $\mathbf{1 6 . 9 - 2 9 . 5}$ & 0.0 & $\mathbf{1 7 . 2}-\mathbf{2 5 . 7}$ & 0.0 \\
\hline Slightly warm $(\mathbf{1})$ & $\mathbf{2 9 . 6 - 4 1 . 7}$ & 1.0 & $\mathbf{2 5 . 8}-\mathbf{3 5 . 2}$ & 1.0 \\
\hline Hot (2) & $\mathbf{> 4 1 . 7}$ & 1.0 & $\mathbf{> 3 5 . 2}$ & 1.0 \\
\hline
\end{tabular}



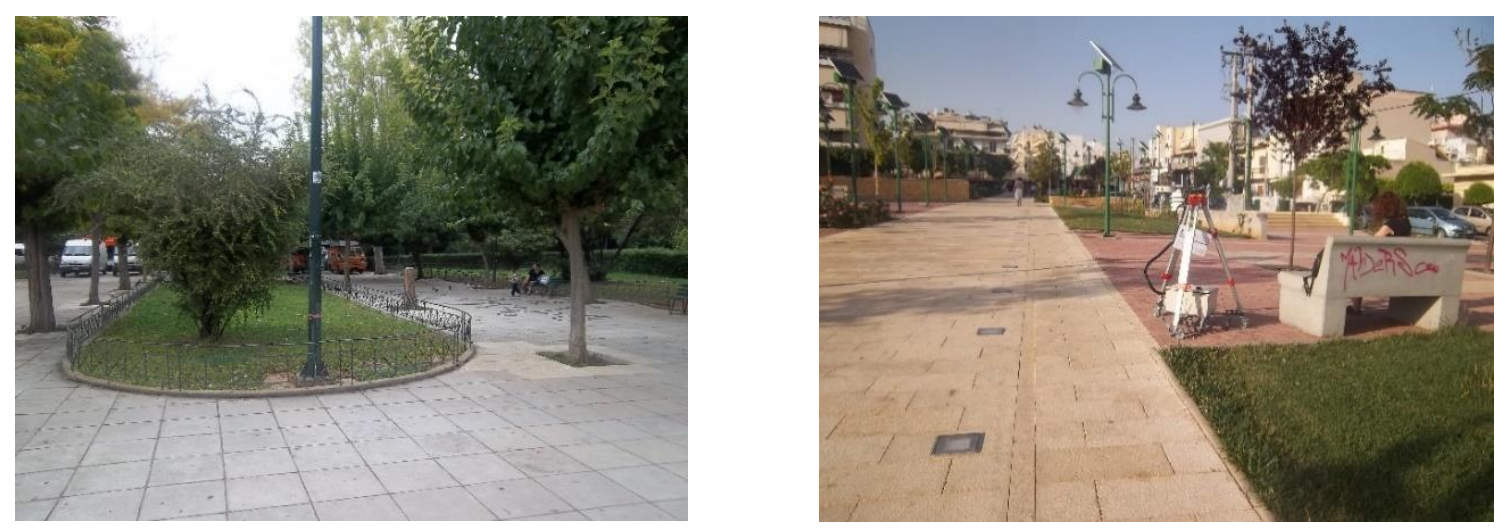

a. Square I

b. Square II

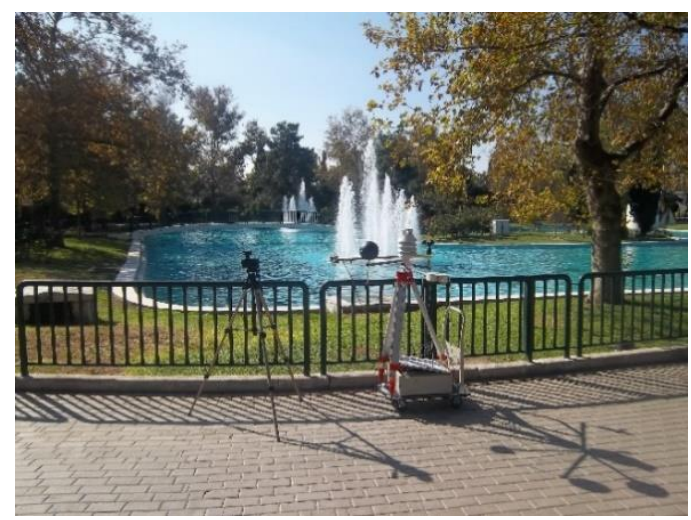

d. Park

Fig 1 


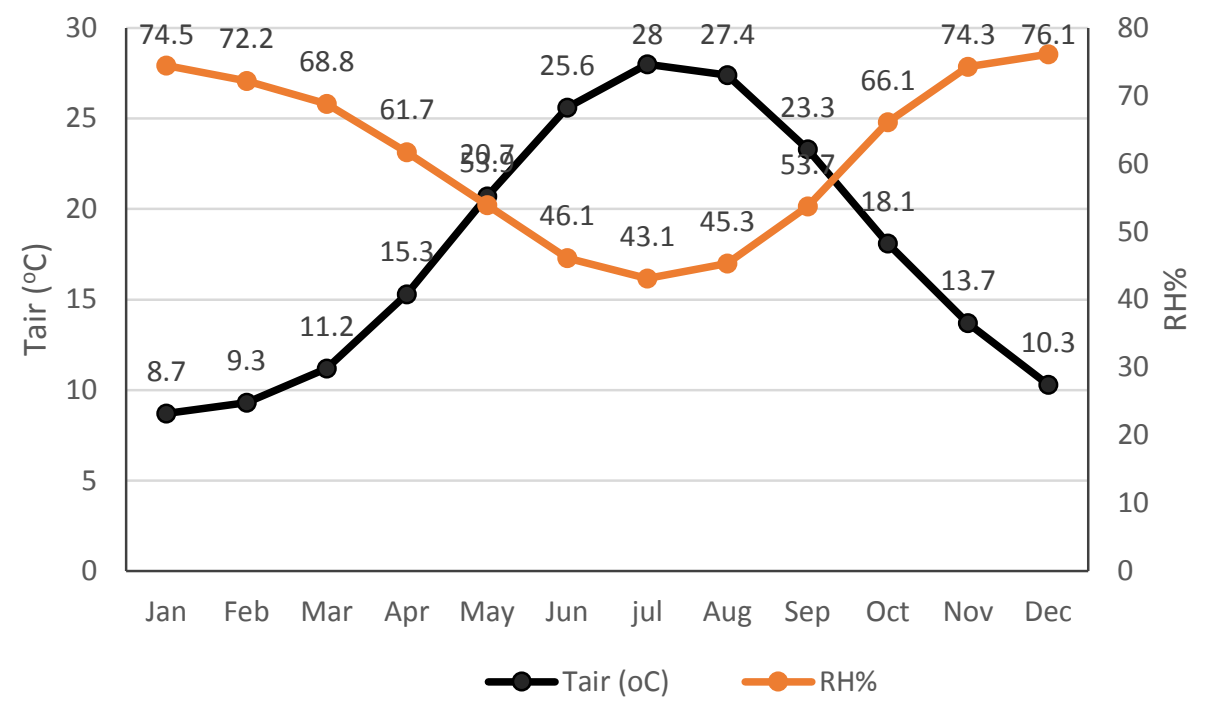

Fig 2 
Tseliou, A., Tsiros, I.X. \& Nikolopoulou, M. Int J Biometeorol (2017). doi:10.1007/s00484-016-1298-5

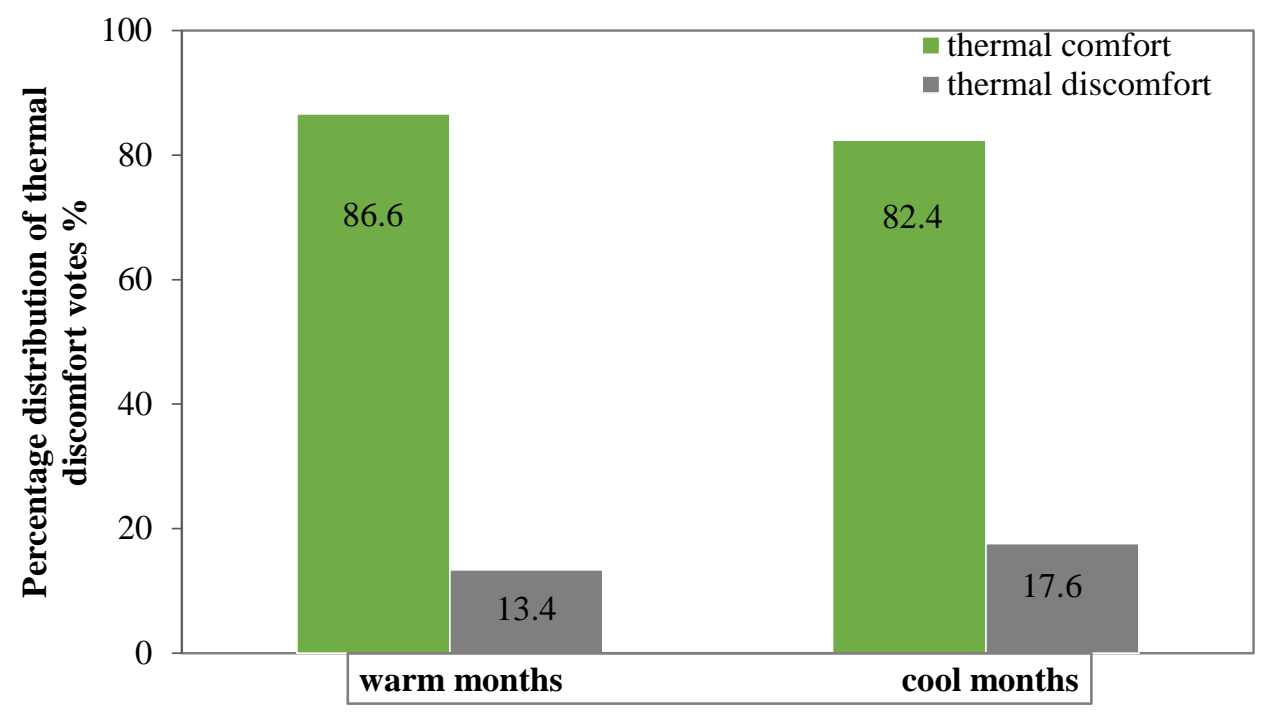

Fig. 3 
Tseliou, A., Tsiros, I.X. \& Nikolopoulou, M. Int J Biometeorol (2017). doi:10.1007/s00484-016-1298-5
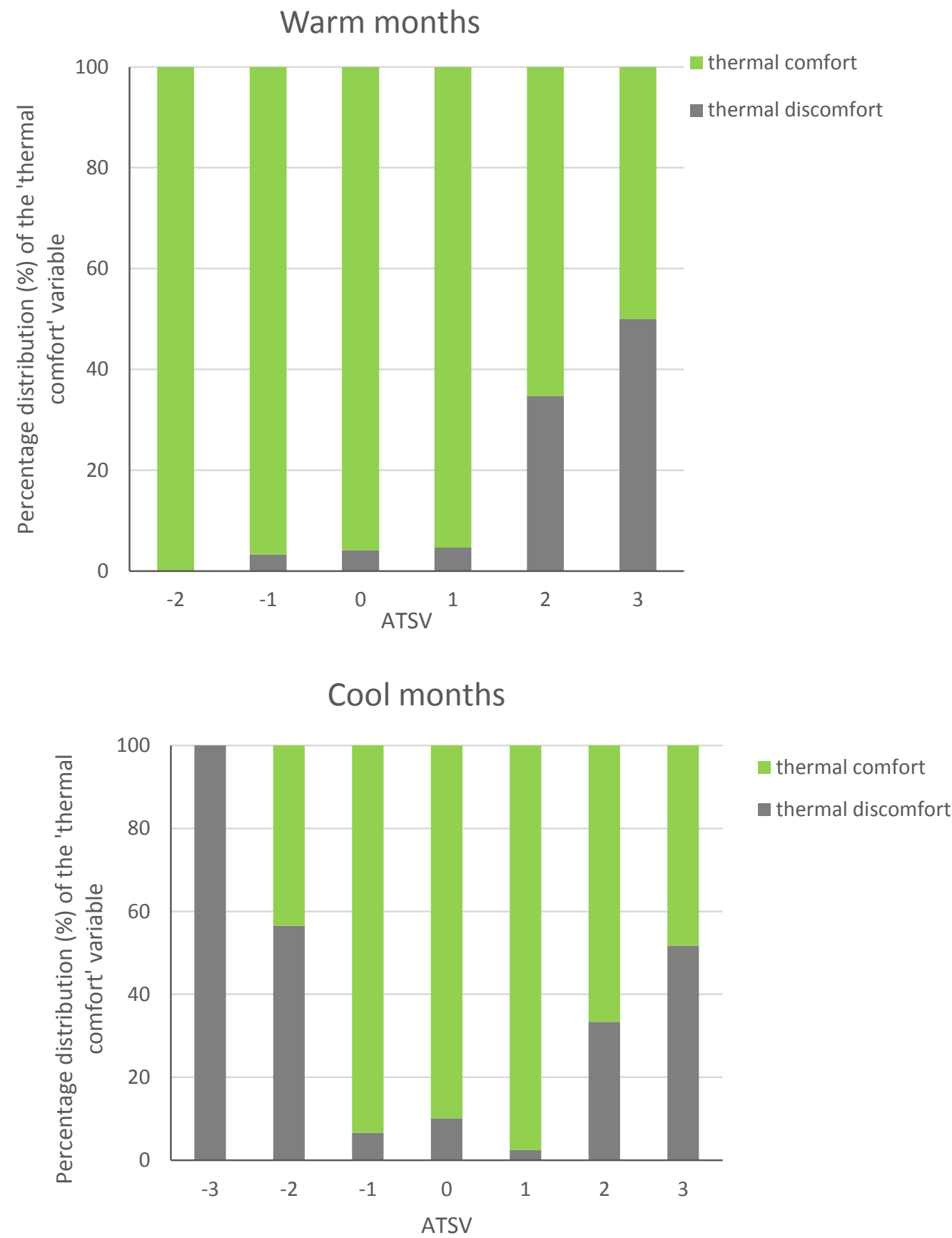

b.

Fig. 4 
Tseliou, A., Tsiros, I.X. \& Nikolopoulou, M. Int J Biometeorol (2017). doi:10.1007/s00484-016-1298-5

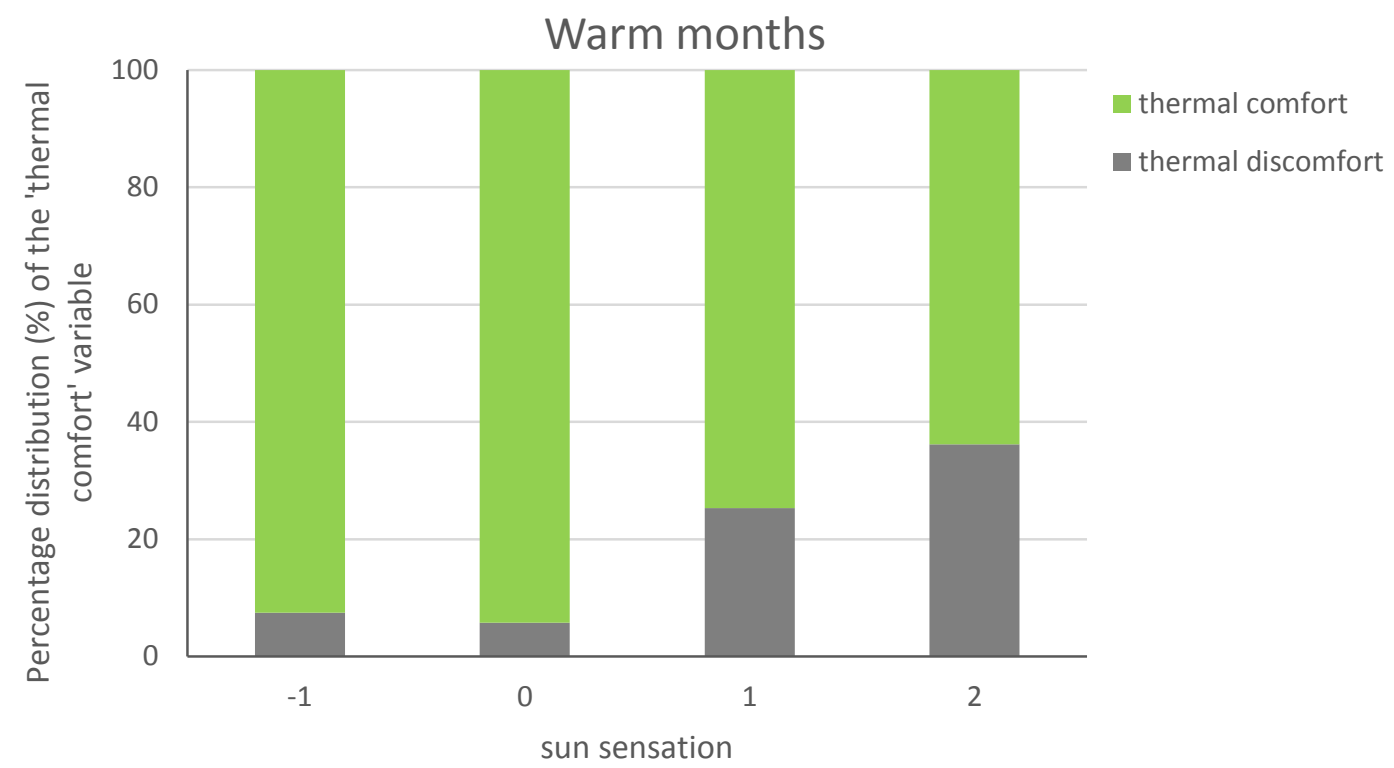

a.

\section{Cool months}

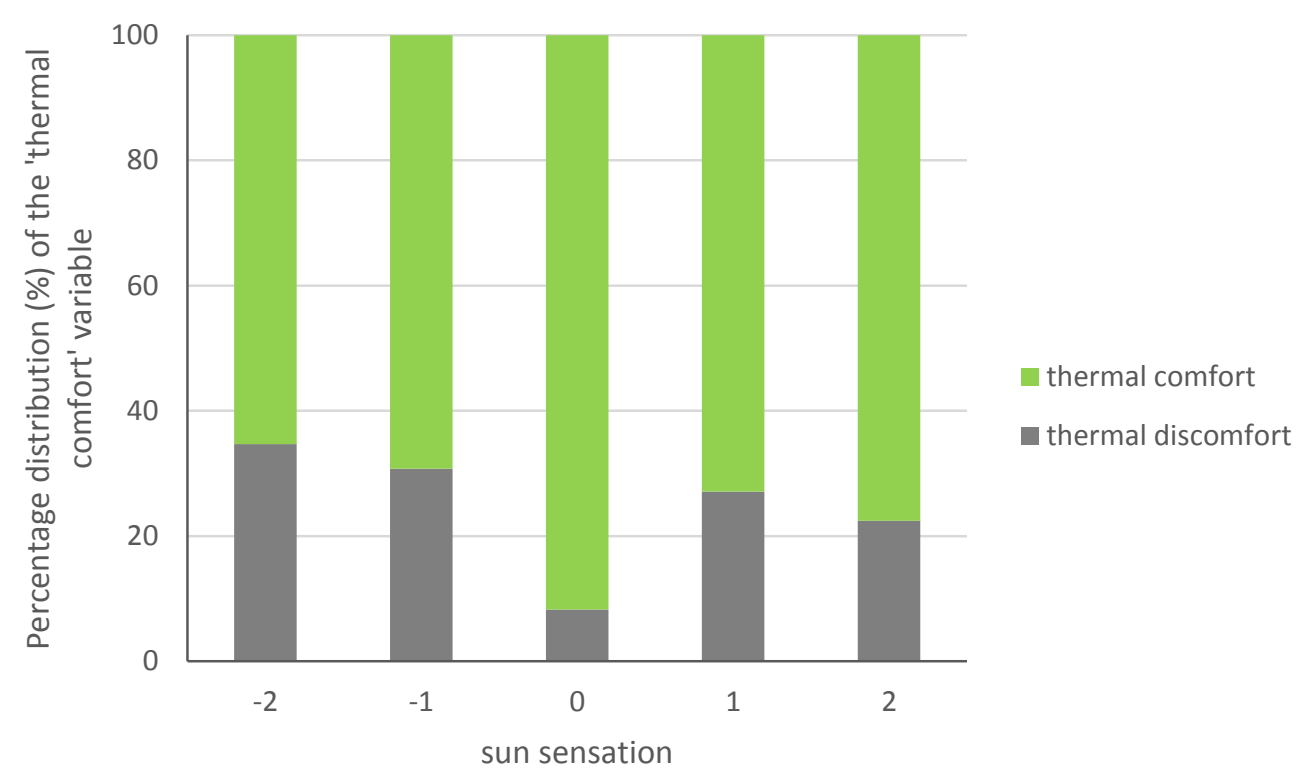

b.

Fig. 5 


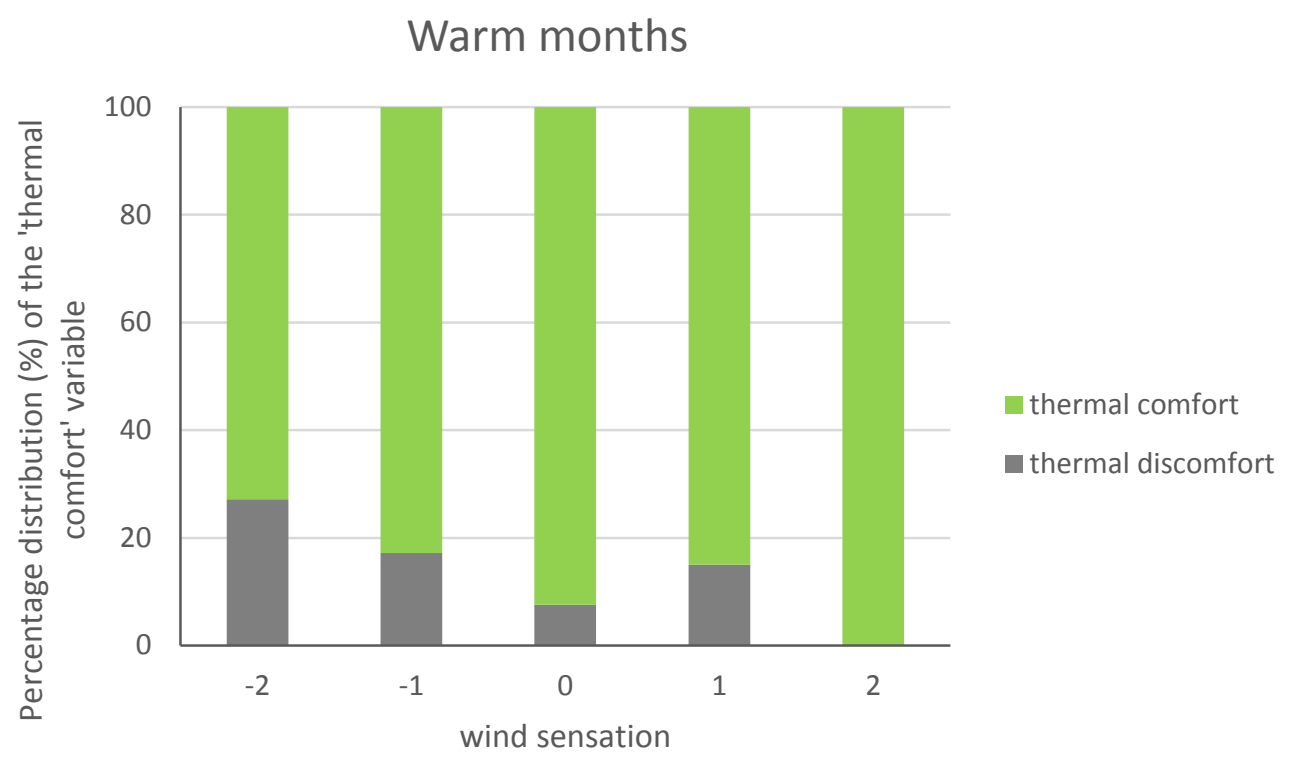

a.

\section{Cool months}

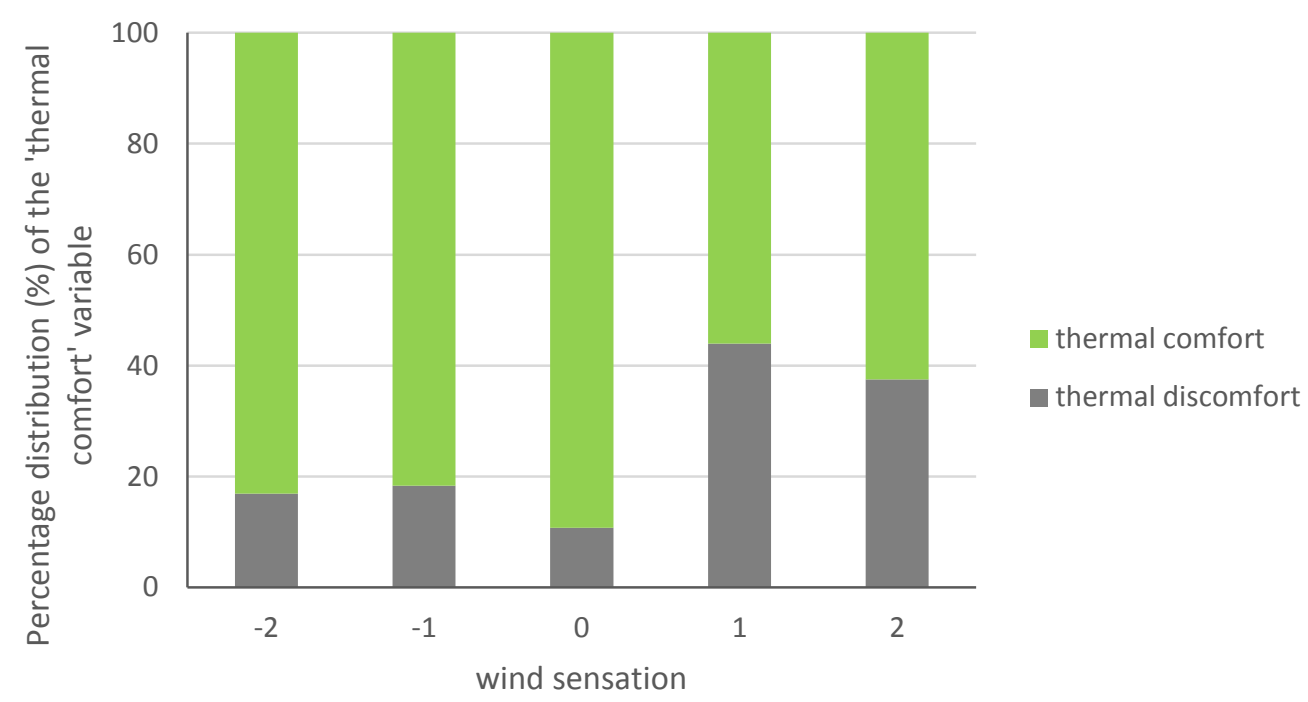

b.

Fig. 6 


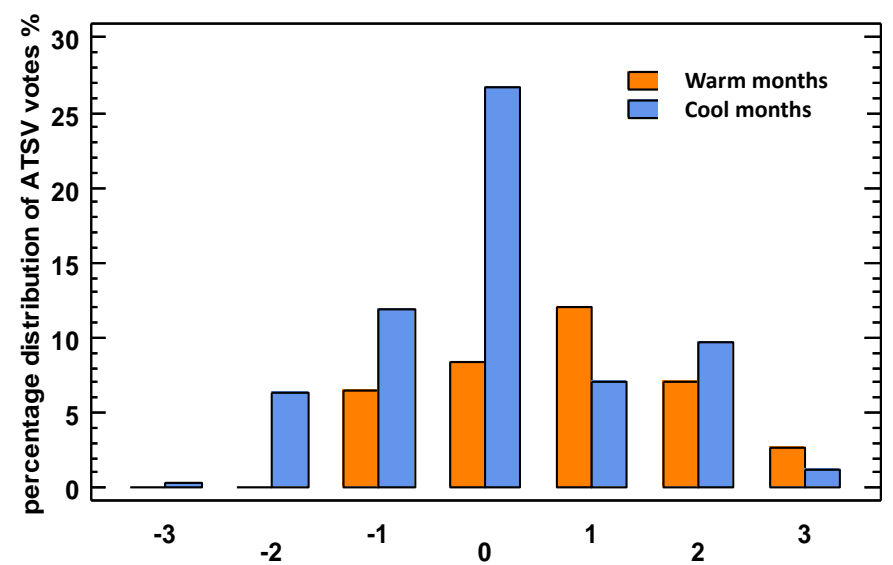

a.

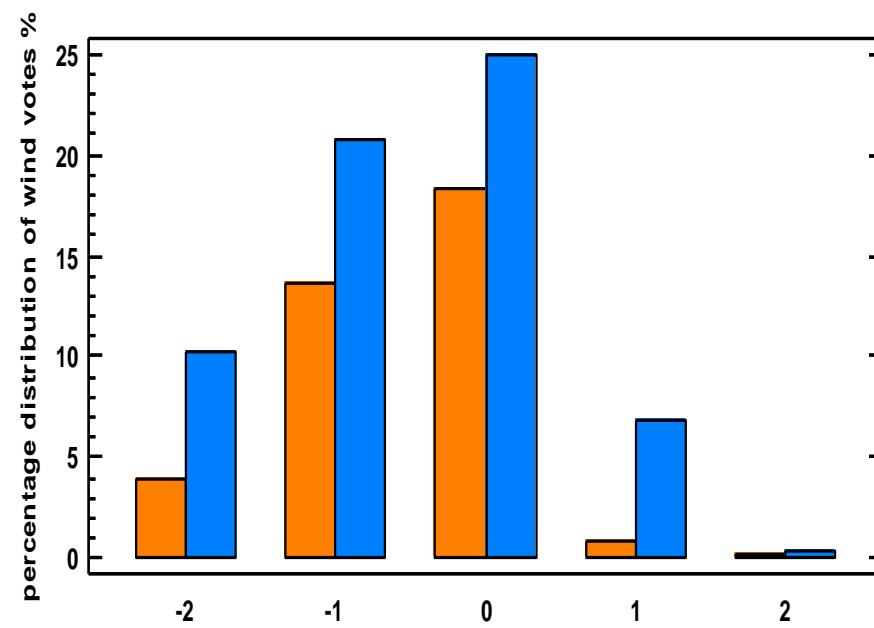

Warm months

Cool months

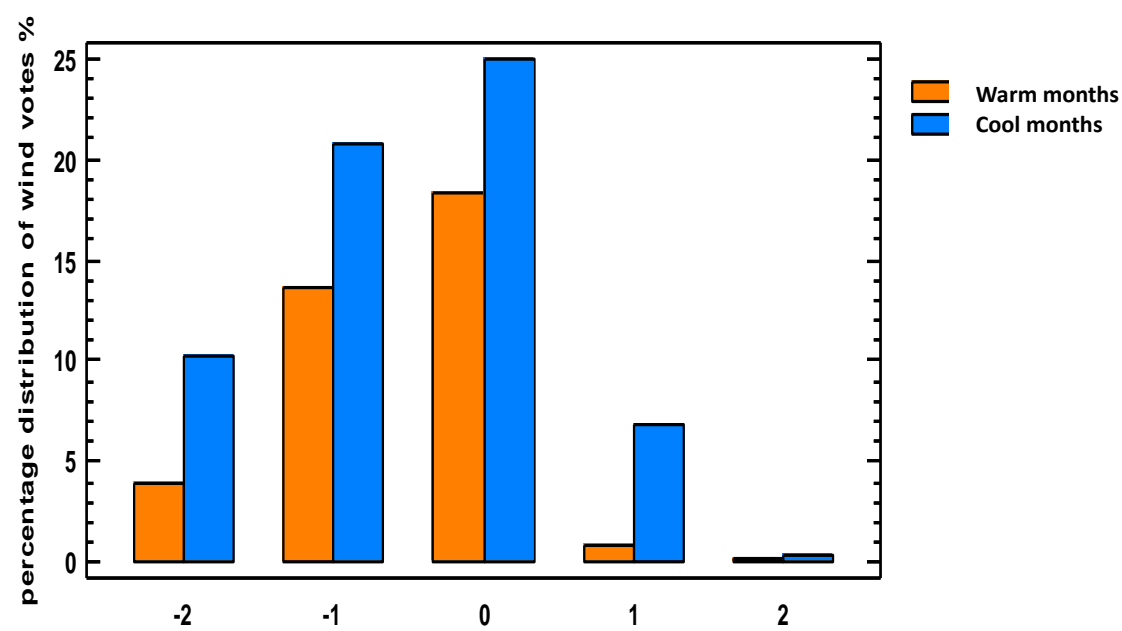

c.

Fig 7 
Tseliou, A., Tsiros, I.X. \& Nikolopoulou, M. Int J Biometeorol (2017). doi:10.1007/s00484-016-1298-5
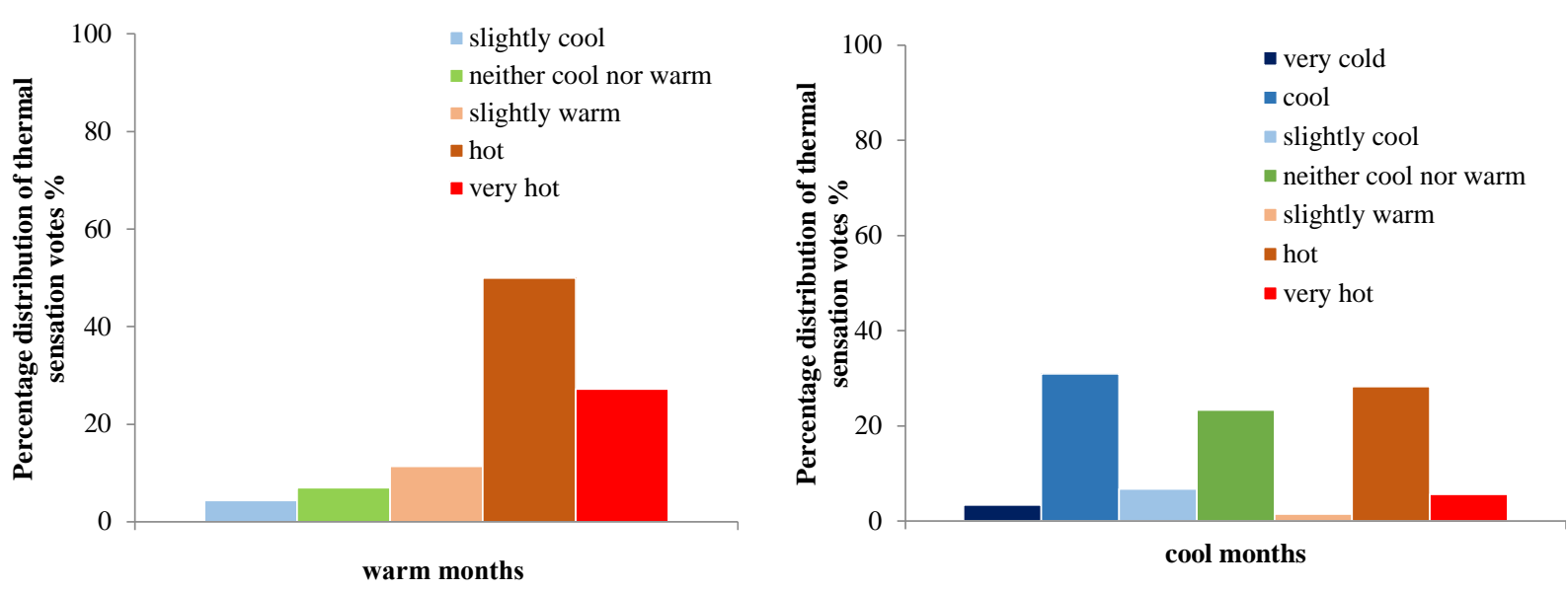

a.

b.

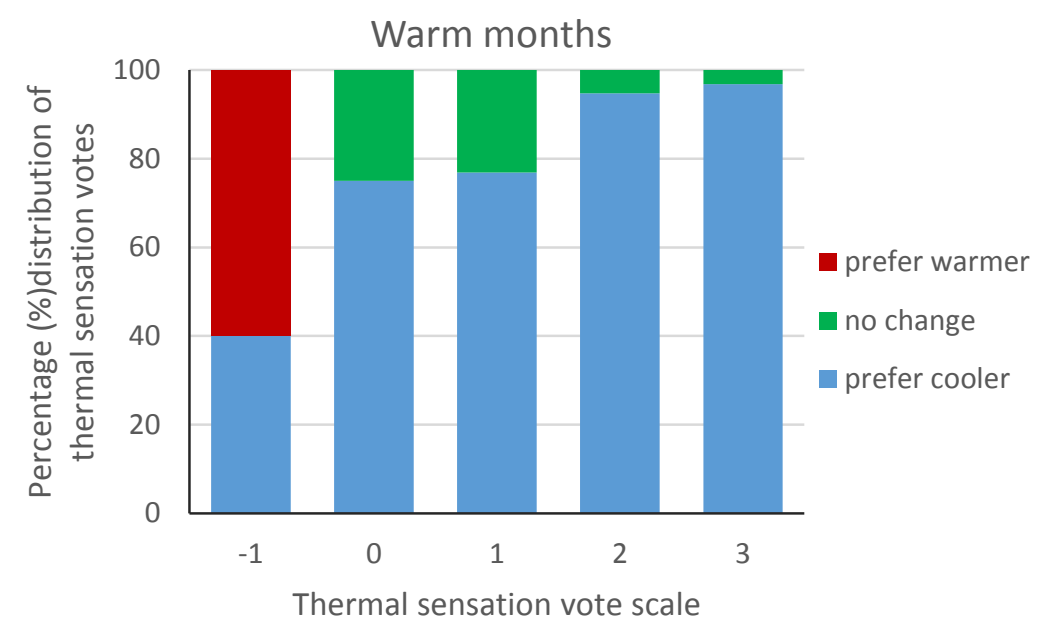

c.

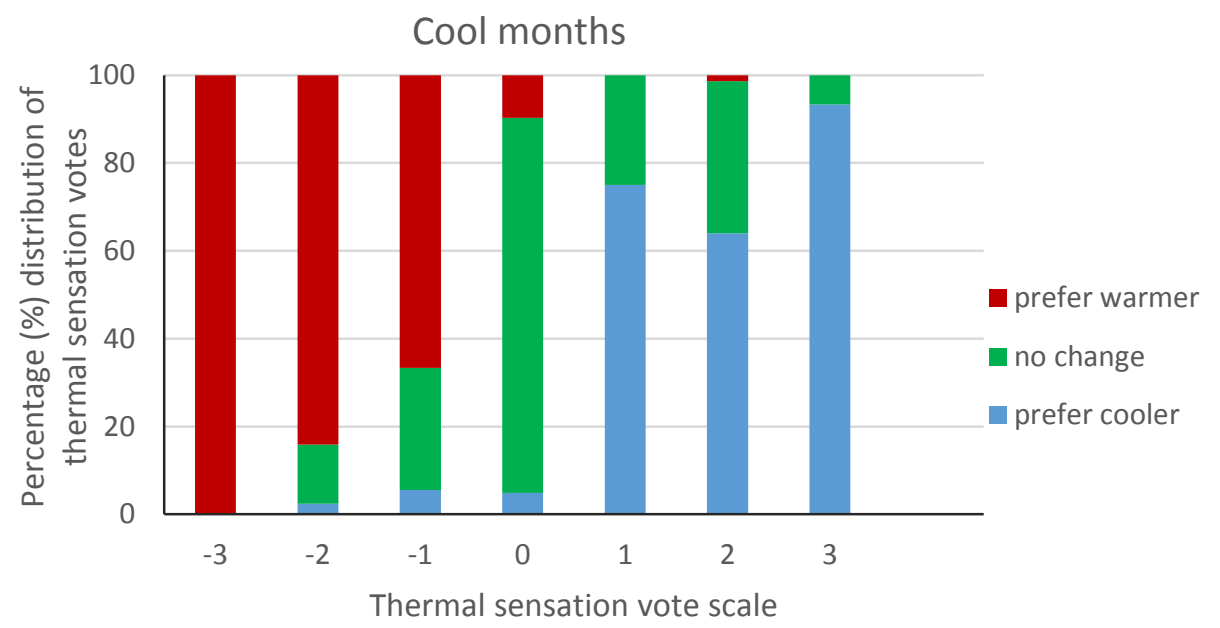

e.

Fig 8 
Tseliou, A., Tsiros, I.X. \& Nikolopoulou, M. Int J Biometeorol (2017). doi:10.1007/s00484-016-1298-5

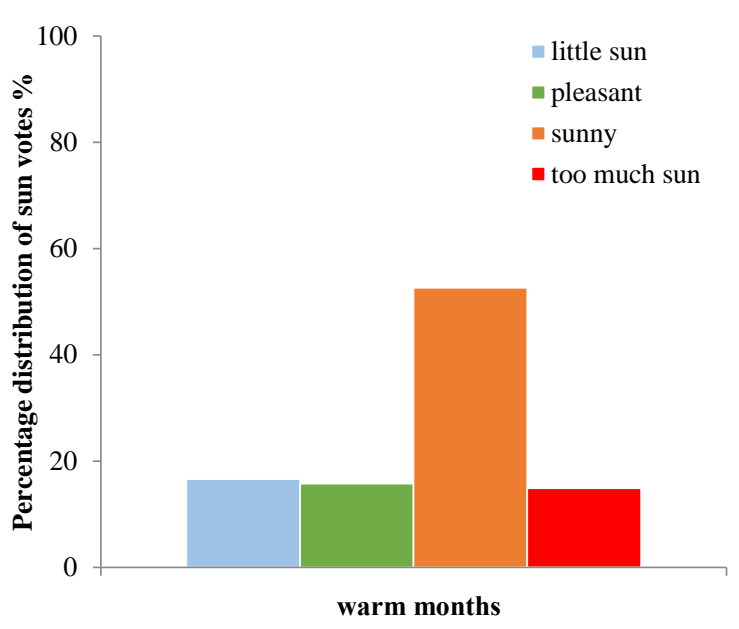

a.

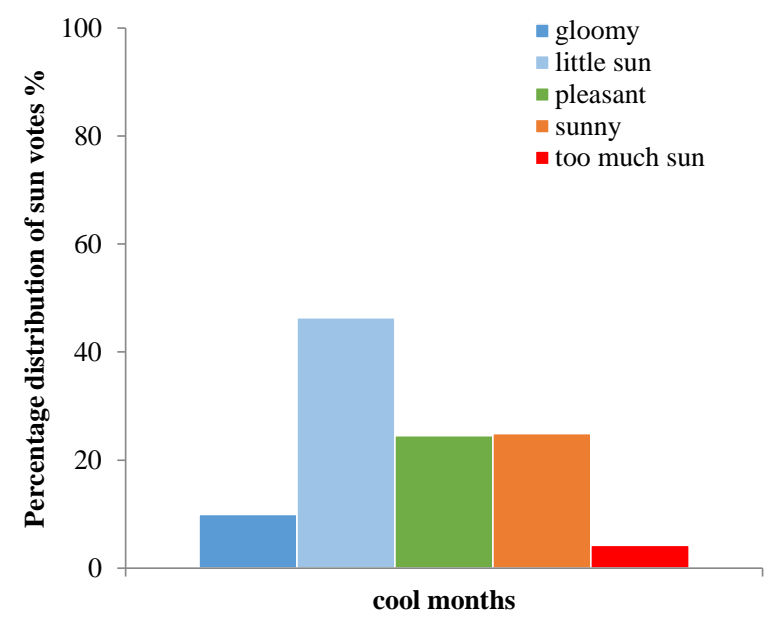

b.

Fig 9 
Tseliou, A., Tsiros, I.X. \& Nikolopoulou, M. Int J Biometeorol (2017). doi:10.1007/s00484-016-1298-5

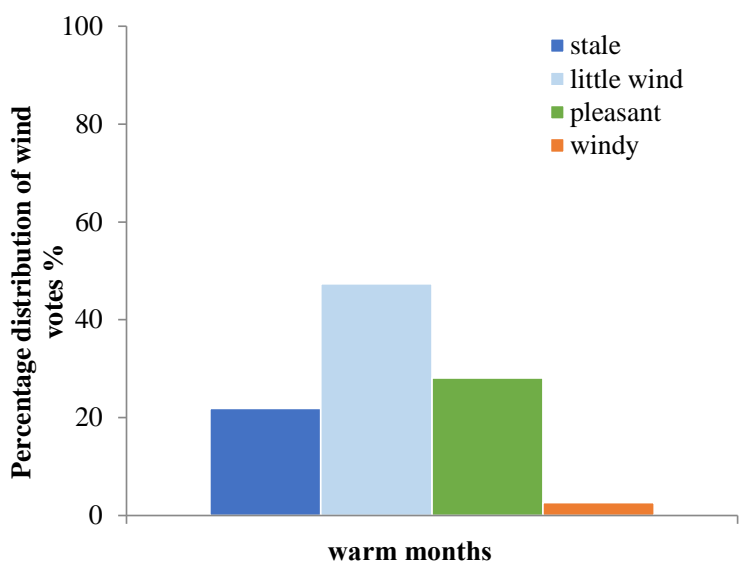

a.

Fig 10

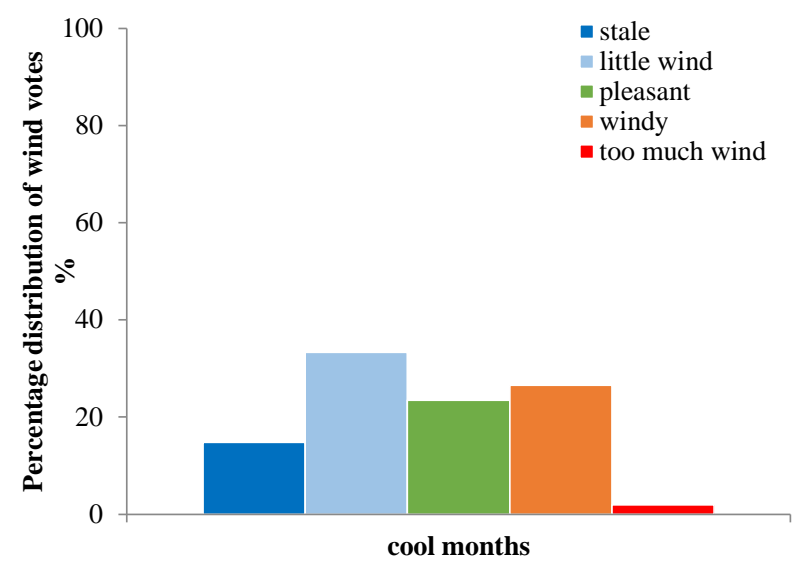

b. 
Tseliou, A., Tsiros, I.X. \& Nikolopoulou, M. Int J Biometeorol (2017). doi:10.1007/s00484-016-1298-5

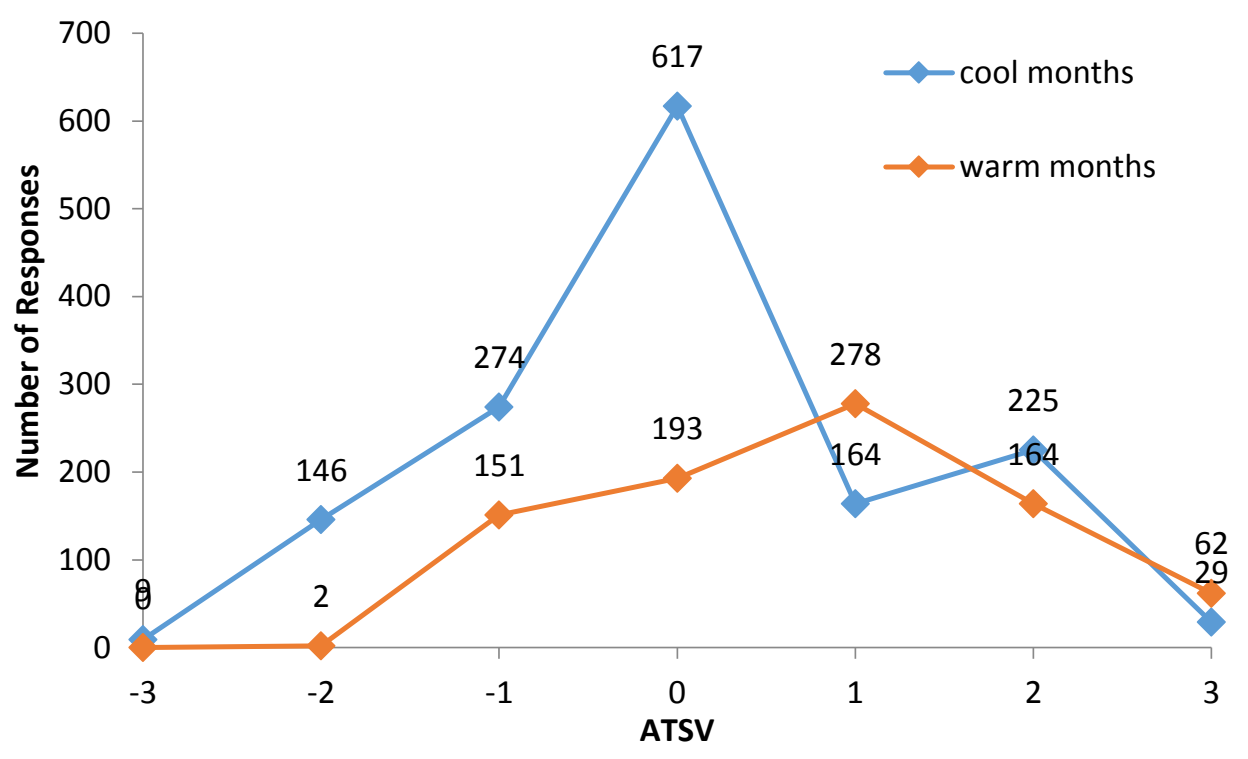

Fig 11 
Tseliou, A., Tsiros, I.X. \& Nikolopoulou, M. Int J Biometeorol (2017). doi:10.1007/s00484-016-1298-5

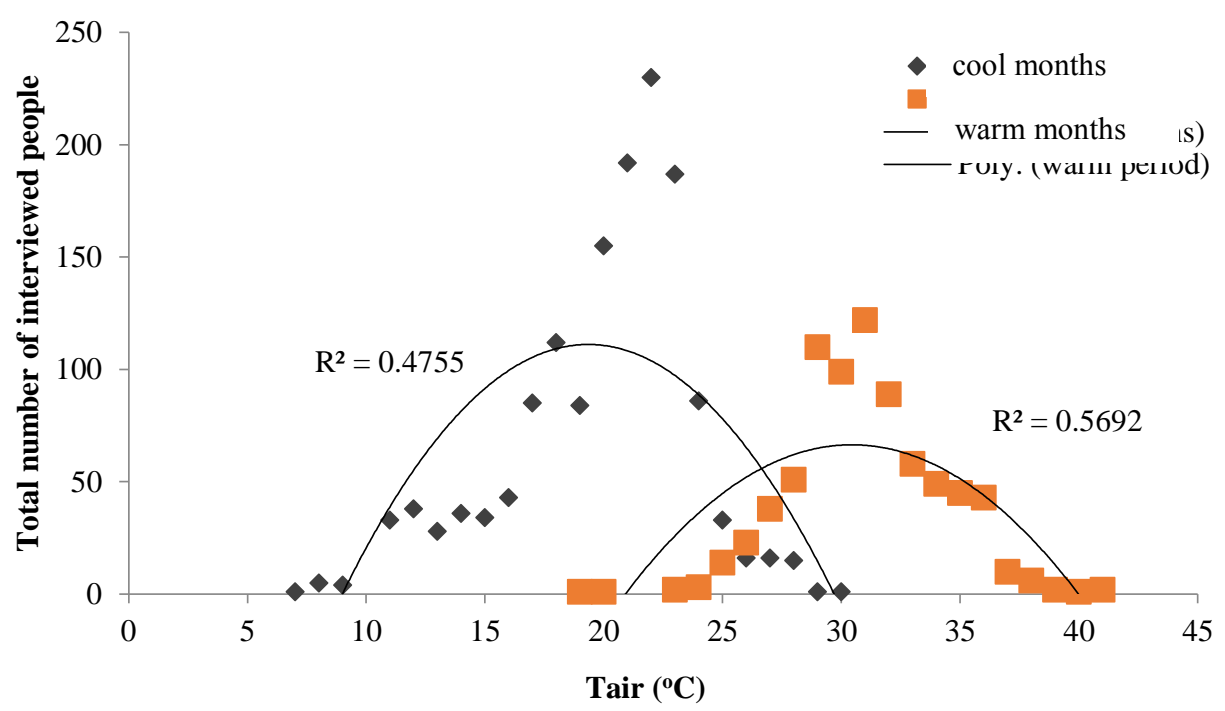

Fig 12 


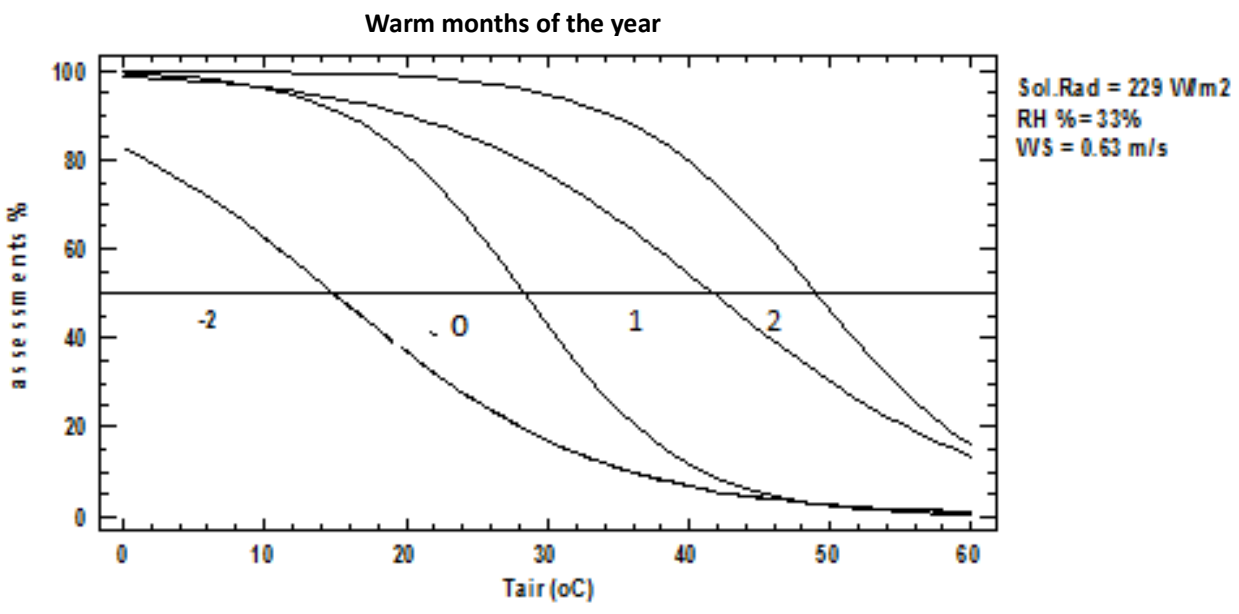

a.

Cool months of the year

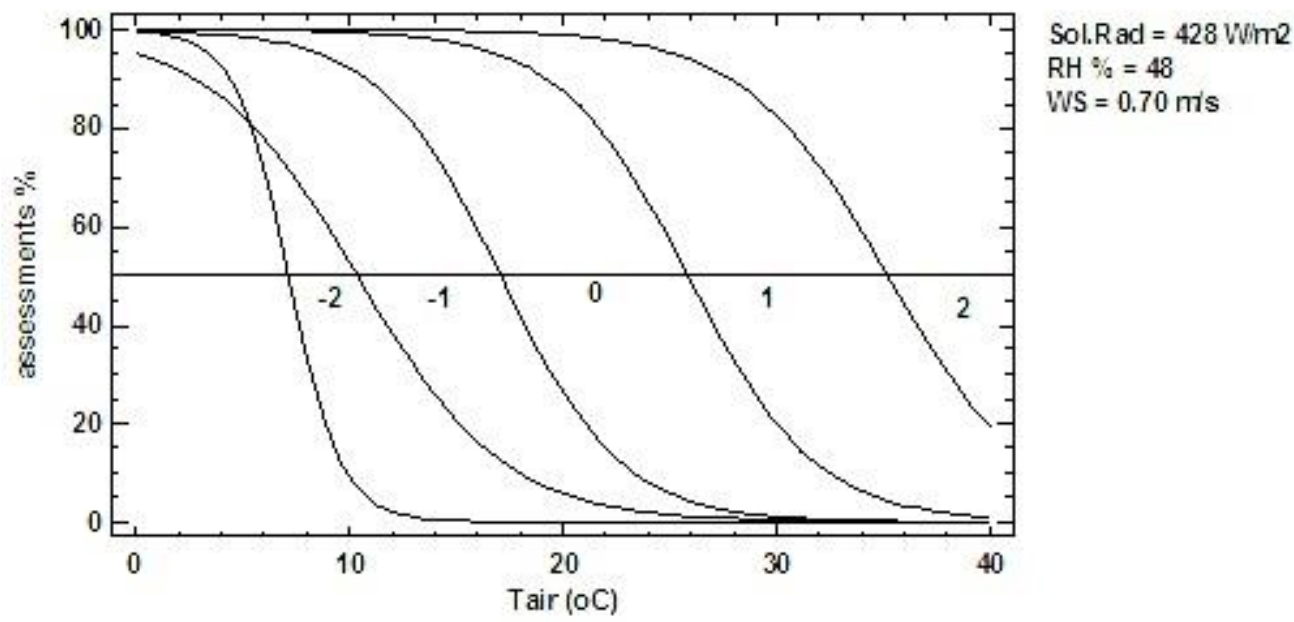

b.

Fig 13 


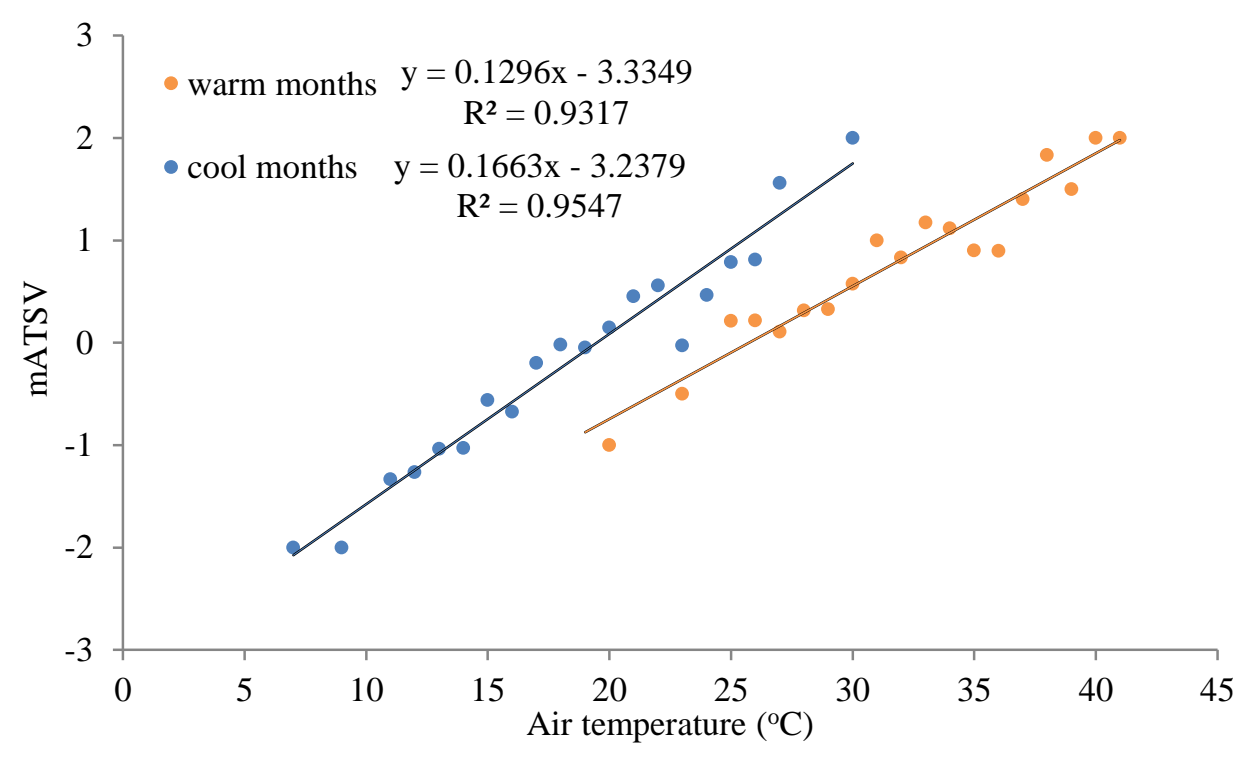

Fig 14 
Tseliou, A., Tsiros, I.X. \& Nikolopoulou, M. Int J Biometeorol (2017). doi:10.1007/s00484-016-1298-5

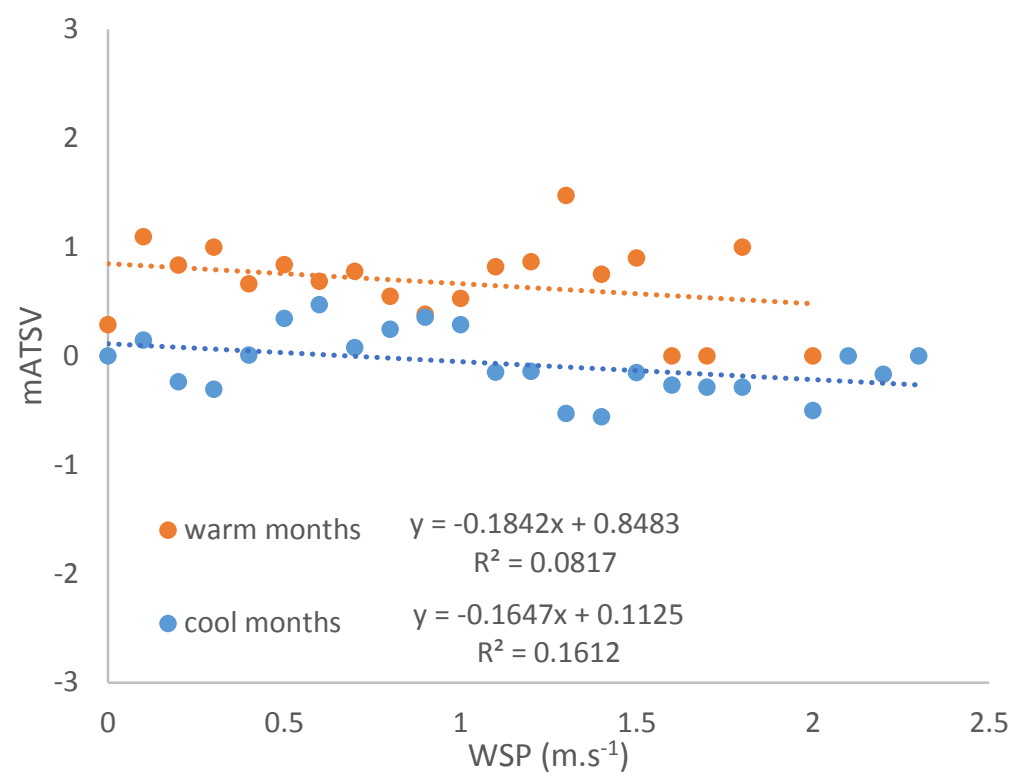

\section{Fig 15}


Tseliou, A., Tsiros, I.X. \& Nikolopoulou, M. Int J Biometeorol (2017). doi:10.1007/s00484-016-1298-5

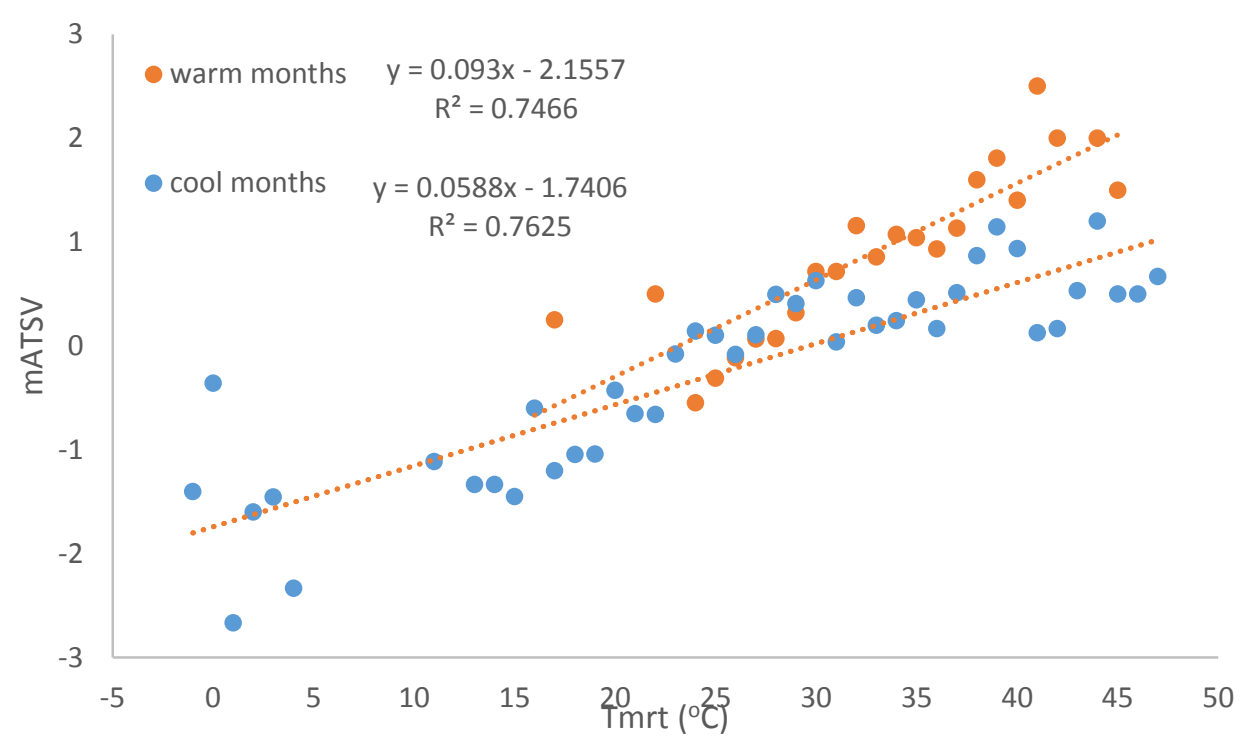

Fig 16 
Tseliou, A., Tsiros, I.X. \& Nikolopoulou, M. Int J Biometeorol (2017). doi:10.1007/s00484-016-1298-5

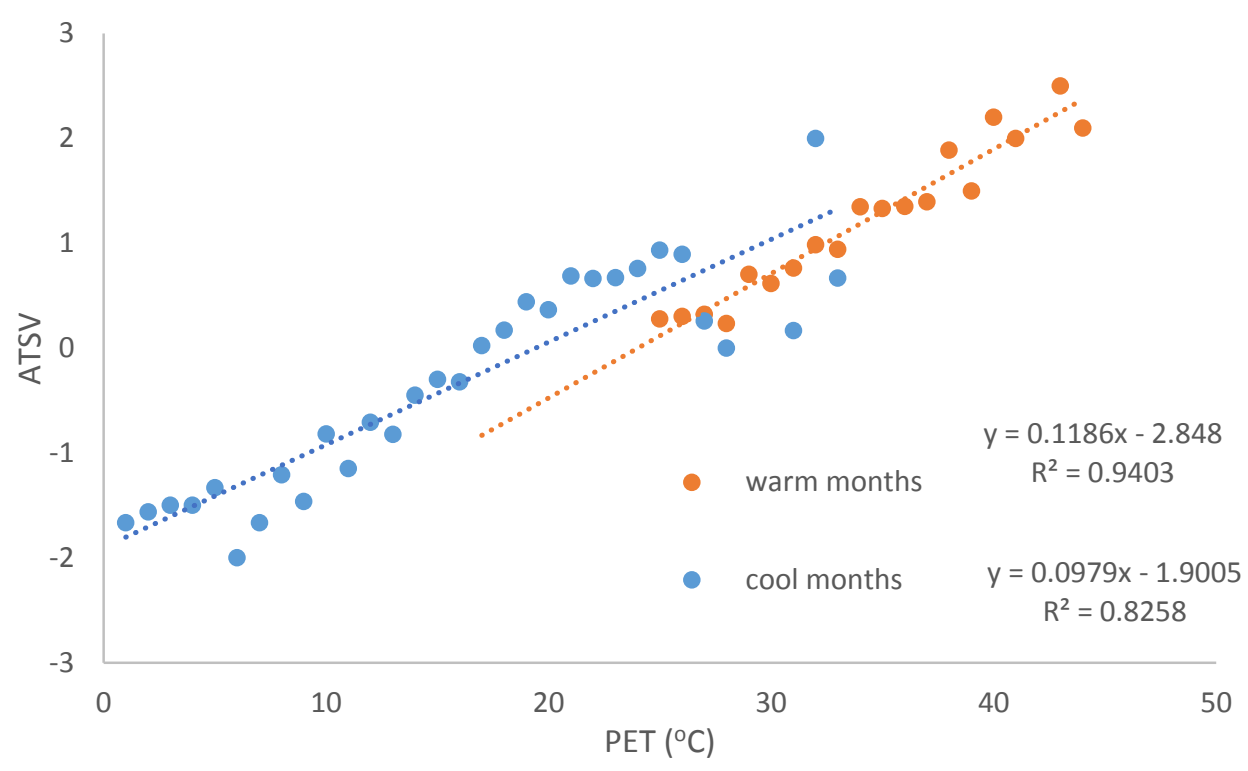

Fig 17 